\title{
De los anillos verdes a las infraestructuras verdes: tres estudio de caso en América
}

From Greenbelts to Green infrastructures: three case studies in America

\author{
Itziar Aguado-Moralejo \\ itziar.aguado@ehu.eus \\ Departamento de Geografía, Prehistoria y Arqueología \\ Universidad del País Vasco/Euskal Herriko Unibertsitatea (UPV/EHU) (España) \\ Carmen Echebarria \\ carmen.etxebarria@ehu.eus \\ Departamento de Economía Aplicada I \\ Universidad del País Vasco/Euskal Herriko Unibertsitatea (UPV/EHU) (España)
}

\author{
José M. Barrutia \\ josemaria.barrutia@ehu.eus \\ Departamento de Economía Financiera II \\ Universidad del País Vasco/Euskal Herriko Unibertsitatea (UPV/EHU) (España)
}

\section{Resumen}

Las políticas de anillos verdes se diseñaron hace ya más de un siglo en Europa para controlar el crecimiento urbano, preservar las tierras agrícolas y conservar la naturaleza, aunque reiteradamente han fracasado en su intento por contener la expansión de la ciudad. Sin embargo, paulatinamente, estas iniciativas han ido incorporando nuevas funciones, incidiendo especialmente en la provisión de servicios ecosistémicos. En Europa, diversos estudios señalan 
que se ha producido una evolución desde los anillos verdes, diseñados a modo de línea de fijación del crecimiento urbano, hacia las infraestructuras verdes mucho más permeables y conectadas. En este artículo, exploramos estas dinámicas a través de la comparación de los casos de tres anillos verdes, Ottawa y Ontario en Canadá y São Paulo en Brasil, implementados en América. Los casos muestran la consolidación de dichas iniciativas y su evolución hacia infraestructuras verdes más amplias, aunque con resultados desiguales en el cumplimiento de los objetivos de las políticas, ya que se requiere disponer de una elevada capacidad de gobernanza para llevar a cabo una gestión coordinada compleja entre los diversos niveles de gobiernos, los diferentes municipios y otros intereses privados y públicos que intervienen en las infraestructuras verdes.

Palabras clave: anillos verdes; infraestructuras verdes; Ottawa; Ontario; São Paulo.

\begin{abstract}
Greenbelt policies were designed more than a century ago in Europe to control urban growth, preserve agricultural land and conserve nature, although they have repeatedly failed in their attempt to contain the urban sprawl. Gradually, these initiatives have been incorporating new functions such as the provision of ecosystem services, with special emphasis on the provision of ecosystem services. In Europe, various studies indicate that there has been an evolution from greenbelts, designed as a containment line for urban growth, to green infrastructures, more permeable and connected. In this article, we explore these dynamics by comparing the cases of three green rings, Ottawa and Ontario in Canada and São Paulo in Brazil, implemented in America. The cases show the consolidation of these initiatives and their evolution towards broader green infrastructures, although with uneven results in the fulfillment of the policy objectives, since a high governance capacity is required to carry out complex coordinated management between the various levels of governments, the different municipalities and other private and public interests involved in green infrastructures.
\end{abstract}

Key words: greenbelts; green infrastructures; Ottawa; Ontario; São Paulo.

\title{
1 Introducción
}

La fragmentación del paisaje como consecuencia, entre otras causas, de la dispersión urbana y del incremento de las infraestructuras de transporte ha derivado en una pérdida de biodiversidad que ha afectado seriamente a los ecosistemas (Barbati et al., 2013; Opdam, Steingröver \& Van Rooij, 2006; Tzoulas et al., 2007; Weber, Sloan \& Wolf, 2006). Por ello, 
desde la planificación urbana se ha recurrido, con frecuencia, a la articulación de anillos verdes con el objetivo de controlar el crecimiento urbano, generar modelos de desarrollo urbano más densos y hacer frente a la depredación de los territorios y paisajes (Macdonald et al., 2021). Sin embargo, en los últimos años, estas iniciativas han ido adquiriendo nuevas funciones relacionadas con la provisión de servicios ecosistémicos tales como la gestión del ciclo hidrológico, la regulación climática, la producción de alimentos, la reducción de la contaminación, la mejora de la salud y el bienestar humano, la provisión de actividades de ocio, etc. (Aziz \& Shah, 2019; Coutts \& Hahn, 2015; Sturzaker \& Mell, 2017). En este contexto, diversos autores (Amati \& Taylor, 2010; Macdonald et al., 2021; Monclús, 2018), han empezado a identificar, en numerosos casos, una evolución desde los anillos verdes hacia las infraestructuras verdes al vincularlas a estrategias territoriales regionales más amplias (Feria \& Santiago, 2017; Thomas \& Littlewood, 2010; Xie et al., 2020).

La evolución desde los anillos verdes tradicionales, con su forma radioconcéntrica específica y centrados principalmente en la contención del crecimiento, hacia las infraestructuras verdes más complejas, con la unión de diferentes áreas verdes o naturales mediante elementos conectores, se puede interpretar como una reinvención de esta herramienta de gestión con objeto de permitir un crecimiento más flexible, reconocer los diversos intereses implicados y corregir las desigualdades geográficas en la provisión de parques y espacios recreativos (Amati, 2008; Evans \& Freestone, 2010). Frente al modelo de anillos verdes que impone restricciones de desarrollo urbanístico, las infraestructuras verdes se plantean como un sistema conectado, más orgánico y sensible a las condiciones del paisaje (Evans \& Freestone, 2010). De este modo, junto con la adición de nuevos espacios naturales a los anillos verdes iniciales e incidiendo de forma especial en los elementos conectores, que favorecen su concepción como un sistema integrado en lugar de espacios aislados (Chang et al., 2012), las infraestructuras verdes adquieren nuevas funcionalidades que permiten incrementar la provisión de los servicios ecosistémicos (Natural England, 2008, 2009; European Commission, 2013).

Así, la diferencia principal entre las infraestructuras verdes y los anillos verdes es el enfoque sistémico y de red otorgada a las primeras (Benedict \& McMahon, 2012), enfatizando así la multifuncionalidad de los espacios que las conforman y la interconexión de dichos espacios (Feria \& Santiago, 2017; Hansen \& Pauleit, 2014). De este modo, permiten mantener la integridad de los distintos hábitats y sustentan la creación de redes ecológicas, favoreciendo la conservación de la biodiversidad y del paisaje, al tiempo que permiten e integran desarrollos urbanísticos (Opdam et al., 2006; Tzoulas et al., 2007). Son de mayor escala, multifuncionales, 
más complejas, y, a menudo, multijurisdiccionales, implicando a diversos municipios y a distintos niveles administrativos e institucionales en su gestión y coordinación (Baxendale \& Buzai, 2019; Keil \& Macdonald, 2016; Macdonald et al., 2021).

En consecuencia, el objetivo de esta investigación es analizar y comparar los casos de tres anillos verdes situados en el continente americano (Ottawa, Ontario y São Paulo), seleccionados por su envergadura y notoriedad y por tener varios puntos en común. Los tres tienen un alcance metropolitano, realizan diversas funciones y aunque sus políticas las establecen los gobiernos de nivel superior, su implementación requiere la coordinación entre diferentes niveles de gobierno, en varios dominios de políticas y en diversos municipios. En el caso de Ottawa, la capital de Canadá, se trata de un área con una amplia tradición en la implantación del anillo verde. Por el contrario, en el caso del anillo verde de São Paulo, Brasil, se trata de un país emergente, con poca trayectoria en la implantación de este instrumento, pero que ha contado con el apoyo de las Naciones Unidas para implementar un anillo verde en el contexto físico de una Reserva de la Biosfera. Por último, se analiza el caso del anillo verde de Ontario en la región de la Gran Herradura de Oro (Greater Golden Horseshoe), región en rápido crecimiento en el sur de Ontario, Canadá, cuyo anillo, uno de los más recientes, fue diseñado para preservar tierras de cultivo y áreas naturales, contener el crecimiento urbano y proporcionar espacios recreativos. El anillo verde se extiende a lo largo de la citada región, caracterizada por su fuerte economía regional, una población multicultural y la intensificación de las presiones de crecimiento urbano y suburbano.

Esta investigación adopta una metodología cualitativa basada en un estudio de casos múltiple, que posibilita entender las similitudes y las diferencias entre los casos al recopilar información de una gran diversidad de fuentes (Baxter \& Jack, 2008). Lo que resta del trabajo se estructura del siguiente modo. En la sección 2, se realiza una revisión de la literatura sobre los anillos verdes y las infraestructuras verdes. En la sección 3, se describe la metodología utilizada, basada en el estudio de casos múltiple. En la sección 4, se abordan los casos en estudio. En la sección 5, se realiza un análisis comparativo de los casos, fijándonos en aspectos relativos a su dimensión, su forma, sus funciones, etc., y se procede a la discusión, contrastando los resultados obtenidos con la literatura previa. Finalmente, en la sección 6 se presentan las principales conclusiones derivadas del trabajo. 


\section{De los anillos verdes a las infraestructuras verdes}

Desde las políticas de planificación urbana y del paisaje, los anillos verdes se han considerado instrumentos esenciales para fijar los límites urbanos y contener el crecimiento y dispersión de las ciudades (Han \& Go, 2019; Siedentop et al., 2016). Sus orígenes se remontan a las propuestas de Ebenezer Howard a finales del siglo XIX en torno a la Ciudad Jardín y a la posterior incorporación en las políticas de planificación regional del Reino Unido a través de la Ley de Planificación Urbana y Rural de 1947 (1947 Town and Country Planning Act) (Amati et al., 2010). A nivel internacional, encontramos múltiples ejemplos que han sido exitosos en el control de la dispersión urbana o la preservación de espacios naturales: Seúl (Yokohari et al., 2000), Londres (Amati \& Yokohari, 2006), Colonia (Timpe, 2020), Frankfurt (Xie et al., 2020), Medellín (Echeverry, 2019), Córdoba (Argentina) (Ruggia \& Occhionero, 2019) etc. No obstante, a pesar de los beneficios que el control de la difusión urbana aporta al logro de la sostenibilidad, estos instrumentos han sido criticados por ser arbitrarios en la fijación de sus límites, incumpliendo criterios de justicia espacial, y por contribuir al encarecimiento de los precios de la vivienda en el interior de las ciudades (Morrison, 2010; Daniels, 2010).

Las infraestructuras verdes se pueden definir como un conjunto de espacios verdes interconectados mediante diferentes elementos (corredores ecológicos, cursos de ríos, sendas urbanas, etc.), que se pueden dar en todas las escalas espaciales (Mansor et al. 2012). Constituyen, a pesar de su reciente aparición como política de planificación (Seiwert \& Rößler, 2020), una síntesis de diferentes políticas con un gran potencial para combinar perspectivas ecológicas, sociales y económicas (Hansen \& Pauleit, 2014). Sus orígenes, los podemos encontrar en la formación de anillos verdes y en la planificación del paisaje (Ahern, 2007; Mell, 2017). Sin embargo, en los últimos años, diversos anillos verdes municipales han dejado de considerarse una solución eficaz para la contención del crecimiento urbano (Han \& Go, 2019; Keil \& Macdonald, 2016; Thomas \& Littlewood, 2010; Xie et al., 2020). En este marco, las infraestructuras verdes se presentan como una iniciativa más flexible y multifuncional que permite dirigir el crecimiento urbano protegiendo espacios verdes y áreas naturales y consolidando estos espacios en forma de red (Amati \& Taylor, 2010). Así, un hecho diferenciador frente a la planificación tradicional, que vería en el crecimiento de las superficies urbanizadas una amenaza, es que tienen en cuenta los desarrollos urbanísticos y la gestión del crecimiento urbano y la construcción de infraestructuras (Chang et al., 2012). De este modo, las infraestructuras verdes persiguen conservar la integridad de los hábitats y constituyen la base física de las redes ecológicas (Ahern, 2007), alcanzando una conectividad que contribuye a 
ampliar los servicios ecosistémicos y a mejorar la integración de los espacios verdes y naturales con la infraestructura gris (Tzoulas et al., 2007; Zhang et al., 2019). Cambia, por tanto, la escala de planificación, que se amplía respecto a la de los anillos verdes, que con frecuencia se limitaba a la escala municipal, y obliga a nuevos modelos de gestión más coordinada entre diversos niveles de autoridades (municipales, provinciales, regionales y nacionales), múltiples áreas de actuación política y otros intereses privados, públicos y de la sociedad civil (Grădinaru \& Hersperger, 2019; Macdonald et al., 2021; Monclús, 2018). En la Tabla 1 se sintetizan las principales características de una y otra política.

\section{Tabla 1. Anillos verdes versus Infraestructuras verdes}

\begin{tabular}{|c|c|c|}
\hline & Anillo verde & Infraestructura verde \\
\hline Origen & $\begin{array}{l}\text { El concepto de anillo verde se basa en la } \\
\text { idea de Ciudad Jardín de Ebenezer } \\
\text { Howard, propuesta a finales del siglo XIX } \\
\text { e introducida en la política de } \\
\text { planificación del Reino Unido en la } \\
\text { década de } 1930 \text { por Raymond Unwin, } \\
\text { Patrick Abercrombie and Frederic Osborn, } \\
\text { entre otros (Amati \& Taylor, 2010; } \\
\text { Bengston \& Youn, 2006). }\end{array}$ & $\begin{array}{l}\text { El concepto de infraestructura verde surge a } \\
\text { finales del siglo XX, también en el Reino } \\
\text { Unido, configurándose como una política } \\
\text { multifuncional que persigue múltiples } \\
\text { propósitos y que involucra a diversos } \\
\text { municipios y a distintos niveles administrativos } \\
\text { e institucionales (Feria \& Santiago, 2017; Keil } \\
\text { \& Macdonald, 2016; Young et al., 2014). }\end{array}$ \\
\hline Objetivo & $\begin{array}{l}\text { Se desarrollan, principalmente, mediante } \\
\text { planes urbanos con el fin de paliar la } \\
\text { expansión de las áreas urbanizadas y sus } \\
\text { efectos sobre las áreas naturales de } \\
\text { proximidad (Amati, 2008; Sturzaker \& } \\
\text { Mell, 2017). }\end{array}$ & $\begin{array}{l}\text { Se desarrollan por motivos de practicidad, al } \\
\text { dejar de ser considerados los anillos verdes } \\
\text { como soluciones eficaces para la contención } \\
\text { del crecimiento urbano, y para suministrar } \\
\text { múltiples servicios ecosistémicos a través de la } \\
\text { conexión de espacios verdes multifuncionales } \\
\text { y la integración de la infraestructura verde con } \\
\text { la infraestructura gris (Hansen \& Pauleit, 2014; } \\
\text { Thomas \& Littlewood, 2010; Tzoulas et al., } \\
\text { 2007). }\end{array}$ \\
\hline Morfología & $\begin{array}{l}\text { Una definición estricta de anillos verdes } \\
\text { implica un cinturón o buffer de áreas } \\
\text { naturales, verdes o agrícolas que rodea la } \\
\text { ciudad. Se distinguen diferentes } \\
\text { tipologías: área física de espacio libre que } \\
\text { rodea una ciudad y actúa de barrera } \\
\text { frente al crecimiento urbano (Bengston \& } \\
\text { Youn, 2006), área forestal bien } \\
\text { preservada (Korosteleva \& Korosteleva, } \\
\text { 2018) superficie circular agrícola bien } \\
\text { conservada (Thomas \& Littlewood, 2010; } \\
\text { Xie et al., 2020), etc. }\end{array}$ & $\begin{array}{l}\text { Existen diversas tipologías. Así, Bartesaghi Koc } \\
\text { et al., (2017) distinguen cuatro categorías } \\
\text { principales de infraestructuras verdes: } \\
\text { 1) masas arbóreas, 2) espacios verdes } \\
\text { abiertos, 3) tejados verdes y 4) sistemas } \\
\text { verticales de vegetación o fachadas verdes. } \\
\text { Por su parte, Davies et al. (2006) desglosan } \\
\text { hasta } 42 \text { tipologías diferentes (superficies de } \\
\text { horticultura, parques públicos, cementerios, } \\
\text { zonas deportivas, entre otras). Naumann et al. } \\
\text { (2011), por su parte, distinguen siete } \\
\text { tipologías: áreas protegidas, zonas de } \\
\text { restauración, áreas de usos sostenibles, zonas } \\
\text { multifuncionales, elementos de conectividad } \\
\text { natural, espacios verdes urbanos y espacios } \\
\text { de conectividad artificial). }\end{array}$ \\
\hline
\end{tabular}




\begin{tabular}{|c|c|c|}
\hline & Anillo verde & Infraestructura verde \\
\hline Funcionalidad & $\begin{array}{l}\text { Contención del crecimiento urbano (Amati, } \\
\text { 2008; Amati \& Taylor, 2010; Kühn, 2003; } \\
\text { Taylor et al., 1995; Xie et al., 2020). } \\
\text { Preservación de las tierras agrícolas de } \\
\text { proximidad (Amati \& Taylor, 2010; Kühn, } \\
\text { 2003). } \\
\text { Preservación de la calidad del aire y control } \\
\text { de la polución (Amati \& Taylor, 2010; } \\
\text { Rodrigues et al., 2006). } \\
\text { Prevención de la vulnerabilidad de zonas } \\
\text { con alta tasa de invasión (Xie et al., 2020). } \\
\text { Mitigación del cambio climático (Thomas \& } \\
\text { Littlewood, 2010). } \\
\text { Dotación de espacios recreativos (Tang et } \\
\text { al., 2007). } \\
\text { Fines militares y defensivos, en algunos } \\
\text { países (Jun \& Bae, 2000). }\end{array}$ & $\begin{array}{l}\text { Preservación de espacios abiertos y urbanos } \\
\text { (Benedict \& McMahon, 2012; Deaton \& } \\
\text { Vyin, 2015; Wright, 2011). } \\
\text { Gestión de las aguas superficiales (Ahern, } \\
\text { 2007; Baptiste et al., 2015; Johns, 2019). } \\
\text { Reducción del efecto isla de calor que } \\
\text { provocan los espacios urbanos (Benedict \& } \\
\text { McMahon, 2012; Bartesaghi Koc, Osmond \& } \\
\text { Peters, 2017; Oliveira, Andrade \& Vaz, } \\
\text { 2011). } \\
\text { Provisión de espacios recreativos (Tang et } \\
\text { al., 2007). } \\
\text { Mitigación y adaptación al cambio climático } \\
\text { y control de la polución (Thomas \& } \\
\text { Littlewood, 2010; Wright, 2011). } \\
\text { Implantación de un marco para el } \\
\text { crecimiento urbano (Chang et al., 2012; } \\
\text { European Commission, 2013; Zhang et al., } \\
\text { 2019). } \\
\text { Corredor para favorecer el movimiento de } \\
\text { las especies (Ahern, 2007; Bartesaghi Koc et } \\
\text { al., 2017; Thomas \& Littlewood, 2010; } \\
\text { Zhang et al., 2019). } \\
\text { Mejora de la calidad ambiental y del } \\
\text { bienestar social (TEP, 2005; Mansor et al., } \\
\text { 2012). } \\
\text { Contribución a la mejora de la salud física y } \\
\text { mental de los ciudadanos (Tzoulas et al., } \\
\text { 2007). } \\
\text { Favorece la creación de empleo y la } \\
\text { activación económica, promoviendo la } \\
\text { economía verde (Mell, 2017). }\end{array}$ \\
\hline $\begin{array}{l}\text { Enfoque de } \\
\text { gestión }\end{array}$ & $\begin{array}{l}\text { Gestión jerárquica, donde las políticas de } \\
\text { planificación se diseñan desde el nivel de } \\
\text { gobierno superior (estatal o provincial), } \\
\text { aunque la implementación de las mismas } \\
\text { recae en el gobierno municipal (Han \& Go, } \\
\text { 2019; Macdonald et al., 2021; Xie et al., } \\
\text { 2020). }\end{array}$ & $\begin{array}{l}\text { Gestión compleja entre varios niveles de } \\
\text { gobierno, múltiples ámbitos de actuación } \\
\text { política, diversas jurisdicciones municipales y } \\
\text { otros intereses privados y públicos } \\
\text { (Grădinaru \& Hersperger, 2019; Macdonald } \\
\text { et al., 2021; Monclús, 2018). }\end{array}$ \\
\hline
\end{tabular}

Fuente: elaboración propia

La versatilidad de las infraestructuras verdes permite que actúen de soporte para las actividades humanas y ecológicas (Benedict \& McMahon, 2012), por lo que su planificación debe abordarse desde perspectivas holísticas que integren las preocupaciones sociopolíticas con las ambientales relativas a la planificación del paisaje (Seiwert \& Rößler, 2020). En su planificación, se identifican una serie de principios claves tales como: conectividad, multifuncionalidad, sostenibilidad, coherencia con el modelo territorial local, gestión multiescalar y 
multijuridisccional, integración con la infraestructura gris, participación y compromiso de los actores locales clave, planificación a largo plazo, etc. (Benedict \& McMahon, 2012; Grădinaru \& Hersperger, 2019; Monteiro et al., 2020).

Por último, diversos estudios (Amati \& Taylor, 2010; Keil \& Macdonald, 2016; Macdonald et al., 2021; Thomas \& Littlewood, 2010), señalan que se ha producido una evolución desde los anillos verdes hacia las infraestructuras verdes en Europa. A ello, ha contribuido de manera especial la política desarrollada desde la propia Unión Europea, a raíz de la Comunicación de la Comisión Europea sobre Infraestructuras Verdes: "Infraestructura verde: mejora del capital natural de Europa" (European Commission, 2013), donde se formulaban una serie de objetivos y medidas para integrar la infraestructura verde en las distintas regiones, siendo clave para promover la adopción del concepto de infraestructura verde por parte de los países miembros (Pauleit et al., 2019). Esta estrategia destaca el potencial de las infraestructuras verdes para reducir la fragmentación de los ecosistemas y aumentar la conectividad entre diferentes áreas naturales incluso a través de las fronteras, enfatizando el papel que pueden cumplir las infraestructuras verdes en la cohesión de las regiones. También destaca el papel que juegan las Infraestructuras Verdes, encuadradas en términos de capital natural, en el crecimiento económico y la inversión (Garmendia et al., 2016). Adopta un enfoque de planificación integrado a todos los niveles (local/regional/nacional/transnacional), persiguiendo alcanzar un paisaje más sostenible para el bienestar y la biodiversidad (Lafortezza et al., 2013). A escala nacional, once países europeos han desarrollado sus propias estrategias nacionales de Infraestructuras Verdes (Slätmoet al., 2019). Gracias a la financiación de derivada de distintos fondos europeos (FEDER, FEADER, LIFE+ y Horizon 2020, entre otros), se han acometido proyectos como Green Surge, GrowGreen, etc., vinculados a las Soluciones basadas en la Naturaleza (NbS) (Davies \& Lafortezza, 2017).

Algunos ejemplos reseñables que muestran esta transición desde los anillos verdes hacia las infraestructuras verdes son los siguientes: en Vitoria-Gasteiz donde existen proyectos para conectar el anillo verde que rodea la ciudad con un anillo a escala regional (el Anillo de las Tierras Altas) y con las zonas verdes interiores de la ciudad y con un anillo verde interior (Andrés Orive \& Dios Lema, 2012; Aguado et al., 2013); en Viena se están acometiendo actuaciones similares realizándose un ejercicio de planificación de los espacios libres a gran escala, tanto desarrollando nuevas áreas verdes como convirtiendo pequeñas áreas verdes ya existentes en áreas más extensas y otorgándoles una mayor protección (Breiling \& Ruland, 2008); en el Área metropolitana de Milán se está desarrollando una política de desarrollo de infraestructuras verdes 
en la que se incorporan los anillos verdes de Turín o Módena, la construcción de 10000 hectáreas de bosques (conocido como Sistema Verde) y el establecimiento de una red ambiental regional que incluye corredores ecológicos conectando las principales áreas verdes de la región con objeto de promover las funciones ecosistémicas (Sanesi et al., 2016); en Irlanda, en las estrategias de planificación espacial del Gobierno Central, se observa también una evolución desde estructuras verdes basadas en el control del crecimiento urbano y la promoción de anillos verdes estratégicos hacia su concepción como una infraestructura esencial para promover la gestión ante los riesgos ambientales aumentando la resiliencia y la capacidad de adaptación de los territorios a los mismos (Douglas et al., 2017). Sin embargo, se puede encontrar una amplia diversidad de propuestas de infraestructuras verdes y su mayor o menor desarrollo suele estar estrechamente relacionado con el nivel de compromiso y apoyo, tanto político como social y económico, que reciben por parte de las instituciones implicadas y de otros actores clave como los representantes del sector privado y de la sociedad civil. En las siguientes secciones, estudiaremos los casos de tres anillos verdes implementados en el continente americano (Ottawa, Ontario y São Paulo), para tratar de determinar si se ha producido una evolución similar a la experimentada en Europa y se han integrado en infraestructuras verdes.

\section{Metodología de investigación}

La investigación se aborda a través de un estudio cualitativo de casos múltiples, una metodología ampliamente utilizada y de gran relevancia en las ciencias humanas y sociales. El estudio de casos múltiple facilita la exploración de un fenómeno dentro de su contexto, brindando la posibilidad de entender las similitudes y las diferencias entre los casos al recopilar información de una gran diversidad de fuentes, pero también permite encontrar los nexos de unión y puntos comunes entre ellos, que favorezca la elaboración de conclusiones generalizables (Baxter \& Jack, 2008). En base a la revisión de la literatura y de los documentos de planificación e institucionales relativos a los distintos casos, en esta investigación se utiliza la aproximación propuesta por Bartesaghi Koc et al. (2017), quienes sugieren un enfoque ternario para abordar la funcionalidad (finalidad, uso, servicios), la estructura (morfología) y la configuración (ordenación espacial) de las infraestructuras verdes. A partir de estos tres elementos clave, se pretende determinar si los tres estudios de caso inicialmente diseñados como anillos verdes han evolucionado hacia infraestructuras verdes, alcanzando esa mayor conectividad, multifuncionalidad y complejidad que caracteriza a las mismas. 


\section{Estudio de tres casos en América}

Los tres casos de estudio se han seleccionado por su relevancia a nivel internacional. El caso del Anillo Verde de Ottawa en Canadá se caracteriza por su amplia trayectoria, siendo Ottawa una ciudad pionera en la implantación de este tipo de iniciativa, inicialmente con el fin de contener el crecimiento urbano y preservar las tierras agrícolas y los hábitats naturales, habiendo incorporado en los últimos años una amplia diversidad de funciones (Campbell, 2019; Taylor et al., 1995). Por su parte, en el caso del Anillo Verde de Ontario también en Canadá se trata de una iniciativa mucho más reciente pero que ha alcanzado una gran notoriedad, tanto por la amplia extensión de superficie que protege y regula como por las complejidades institucionales observadas en su desarrollo (Henstra, 2017; Macdonald et al., 2012; Pond, 2009a, 2009b). Por último, el interés del anillo verde de São Paulo en Brasil, reside en el estudio de un caso desarrollado en un país emergente, con escasa trayectoria en la implantación de este tipo de iniciativas (Moraes Victor et al., 2004; Moreno-Peñaranda, 2021). De ahí, la relevancia del apoyo a esta iniciativa por parte de la Unesco al declarar el área como Reserva de la Bioesfera (Ramos-Ribeiro, 2015).

Los tres casos de estudio seleccionados reciben la denominación de anillos verdes. Sin embargo, en el caso del anillo verde de Ontario se produce una integración de diferentes espacios naturales que incrementan su complejidad morfológica y que no adoptan la forma tradicional de los anillos verdes como espacio circunferencial en torno al área urbanizada. El anillo verde de Ottawa, por sus dimensiones y fecha de puesta en marcha, 1956, se asemeja, en mayor medida, al instrumento de planificación propuesto por Richard Abercrombie a finales de los años treinta del siglo XX en el contexto del Plan de Desarrollo de Londres (Greater London Plan), aunque se presenta en forma de cuñas verdes y no se encuentra íntegramente cerrado. Por último, la Reserva de la Biosfera del Anillo Verde de São Paulo circunda todo el municipio de São Paulo y entraña una gran complejidad debido a las circunstancias políticas, sociales y económicas de la región en la que se inserta. Al analizar estos tres anillos verdes, pretendemos determinar si se ha producido una evolución de los mismos hacia infraestructuras verdes.

\subsection{El Anillo Verde de Ottawa}

El anillo verde de Ottawa abarca 20000 hectáreas de espacios verdes (National Capital Commission-NCC, 2013), incluyendo tierras de cultivo, bosques y humedales. Se trata de una franja en forma de media luna ubicada en el corazón de la Región de la Capital Nacional (ver Figura 1). Tiene una longitud de 45 kilómetros y su anchura varía desde los 2 hasta los 10 
kilómetros. Más del 70\% de su superficie es propiedad del Gobierno de Canadá, aunque la Comisión de la Capital Nacional (National Capital Commission-NCC), Corporación Federal de la región de la Capital de Canadá creada por el Parlamento de Canadá en 1959 que en la actualidad dirige la Ministra de Servicios y Contratación Pública y está constituida por una Junta Directiva y siete comités, es la entidad administradora y responsable de gestionar la mayor parte de las tierras del anillo verde en nombre del Gobierno Federal. Aparte de las funciones iniciales de protección de suelos agrícolas, de especies en peligro de extinción y de conservación de una amplia variedad de hábitats representativos del paisaje canadiense, hoy en día, realiza funciones adicionales. Entre otras, desarrolla una clara función recreativa y turística, con más de $100 \mathrm{Km}$ de senderos que lo recorren y más de 3,5 millones de visitantes cada año (NCC, 2013); dispone de sendas peatonales y ciclistas, instalaciones deportivas, un camping, zona de picnic, espacios habilitados para pasear con perros, etc. Además, alberga una de las estaciones de bloqueo del Canal Rideau, reconocida como Patrimonio de la Humanidad por la Unesco, y se están promoviendo nuevas funciones como el control de las actividades hídricas, la investigación, la agricultura y la silvicultura sostenible, etc., existiendo, asimismo, conexiones con otras áreas verdes próximas que refuerzan el ecosistema global. Por último, éste área proporciona espacio para diversas infraestructuras federales como el Aeropuerto Internacional Macdonald Cartier de Ottawa, el Centro de Investigación de Bell Northern, instalaciones comunitarias de gran tamaño, como el Nepean Sportsplex, el Hospital Queensway-Carleton y el Centro de Detención de Ottawa-Carleton, así como varias escuelas e iglesias. Desempeña, por tanto, un relevante papel en la economía de la comunidad local, ya que, según los últimos datos oficiales disponibles del año 2013, alrededor de 12000 personas trabajan en su interior y cerca de 1000 personas todavía viven en él (NCC, 2013; Gordon \& Scott, 2008). 

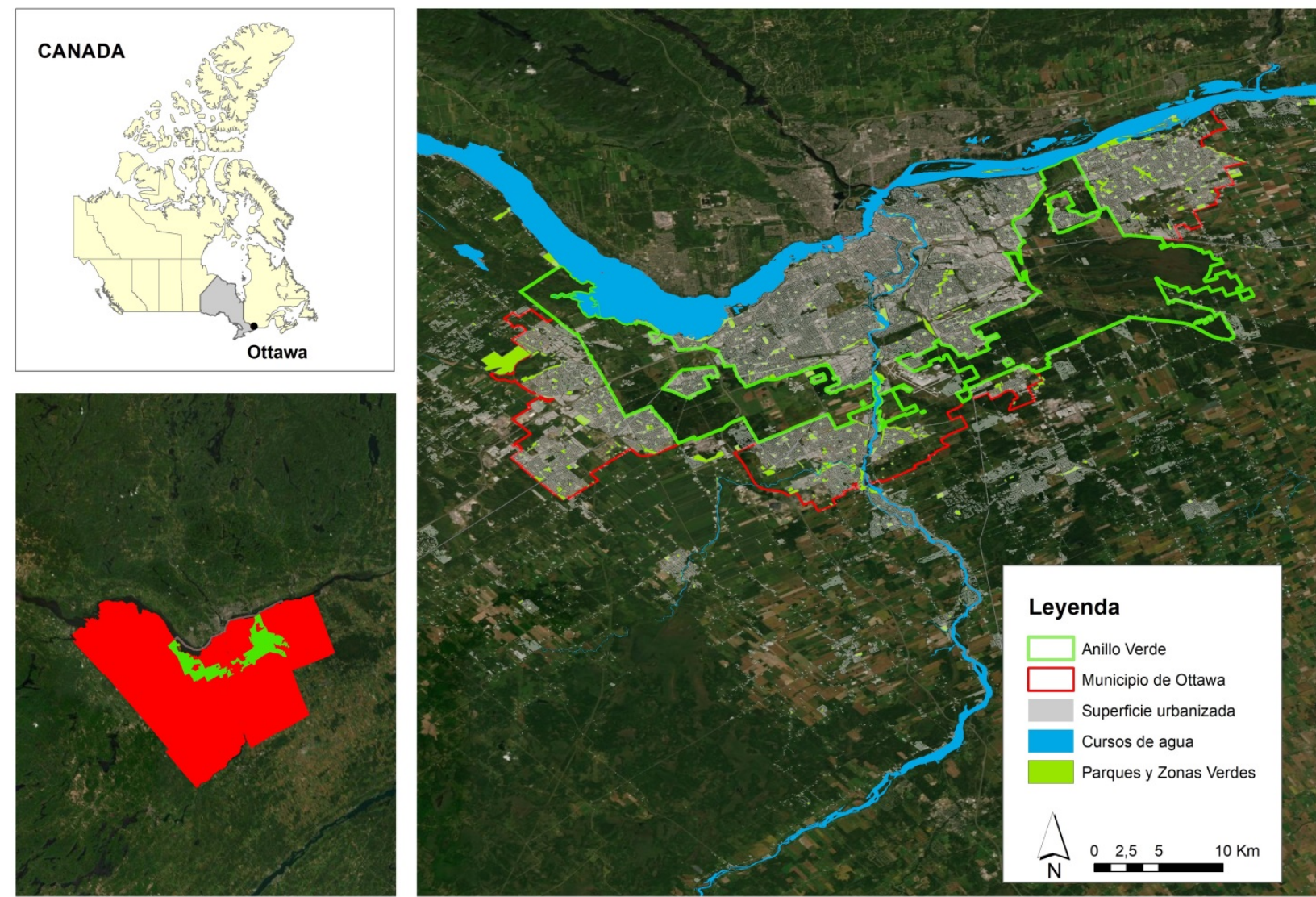

Fuente: elaboración propia a partir de City of Ottawa (2021)

Los orígenes del anillo verde de Ottawa se remontan a 1950 cuando el gobierno de Canadá contrató al arquitecto y planificador francés Jacques Gréber, responsable de la revitalización urbana de París, para mejorar la planificación urbana de la ciudad. El plan propuesto por Gréber fue aprobado por el parlamento canadiense en 1951 y denominado Plan para la Capital Nacional (Plan for the National Capital). De acuerdo con los términos de este Plan, se eliminaron 51 kilómetros de vías férreas y la estación central de tren se desplazó a una región más alejada del centro de la ciudad, al este. También se construyeron muchos parques y zonas verdes alrededor de la ciudad, así como un gigantesco parque, de $36 \mathrm{~km}^{2}$, en la ciudad vecina de Gatineau, el llamado Parque de Gatineau. En 1956, el gobierno de Ottawa puso en marcha un anillo verde alrededor de la ciudad, dentro del Plan para la Capital Nacional (Plan for the National Capital), con el fin de evitar la expansión urbana descontrolada, proteger el paisaje rural y proporcionar espacio para grandes instalaciones. En los años siguientes, los planificadores del gobierno Federal establecieron los límites del anillo verde, cuya superficie se encontraba en aquel momento ocupada por cientos de pequeñas granjas y edificios gubernamentales (Erickson, 2004; Amati \& Taylor, 2010). El hito clave fue la implicación del 
gobierno Federal y la compra de la tierra por parte del mismo. El gobierno Federal no contaba con el apoyo local para la zonificación del área como anillo verde, así que, en 1958, decidió comenzar la compra del terreno. En 1966, ya habían adquirido la mayoría de las tierras por unos 40 millones de dólares de la época, más de un tercio de ellas a través de expropiaciones. Aunque este proceso de compra de tierra por el gobierno contó con una fuerte oposición por parte de los agricultores locales, ya que devaluó el precio de sus tierras y permitió obtener los terrenos al gobierno a un coste muy bajo. Posteriormente, en 1981, se aprobó el Plan de Gestión del anillo verde con el fin de mejorar la conservación de la diversidad en su interior. Desde entonces, al tiempo que el número de tierras de cultivo ha ido en aumento, el número de viviendas se ha ido reduciendo demoliéndose edificios al final de su ciclo de vida. En 1995, el órgano gestor del anillo verde, la Comisión de la Capital Nacional (National Capital CommissionNCC), propuso ampliar el anillo fuera de la zona ya existente, con la intención de incluir zonas de gran sensibilidad ecológica como el pantano de Stony y Mer Bleue.

Uno de los instrumentos de actuación más significativos ha sido el Master Plan del anillo verde (Greenbelt Master Plan) de 1996, elaborado por la Comisión de la Capital Nacional (National Capital Commission-NCC), y cuya revisión y actualización fue publicada en 2013 y permanece en vigor hasta 2023 (NCC, 2013). En este documento se recogen las líneas de actuación prioritarias para los próximos años. Entre las propuestas de cambio que se realizan en la revisión del Plan, se encuentra la calificación de suelos en cinco grandes tipos: núcleo de suelo natural, conectores naturales, usos agrícolas, instalaciones y usos federales e instalaciones y usos no federales. Con ello, se pretende simplificar las tipologías de suelos y proporcionar un reflejo más claro respecto de la intención del uso de estos terrenos a largo plazo.

Al igual que ha evolucionado a lo largo del tiempo, seguirá haciéndolo según vayan cambiando las prioridades nacionales y regionales. En esta línea, el Master Plan del anillo verde de 2013 (Greenbelt Master Plan) proporciona las bases para su preservación y desarrollo, donde se prevé la conversión del anillo verde en una red interconectada de espacios verdes, entre los que resulta interesante incluir tierras agrícolas, especialmente orientadas a una agricultura más sostenible y viable. En este sentido, se está realizando una apuesta decidida por una agricultura orgánica que utilice de manera óptima los recursos naturales, e incluso movimientos como Local Food están obteniendo un desarrollo muy relevante (Ballamingie \& Walker, 2013). De hecho, la revisión de 2013 recomienda ampliar los espacios naturales incluidos dentro del anillo verde añadiendo 2400 hectáreas de tierras adyacentes y destinar un 23\% de las tierras agrícolas a agricultura sostenible para alcanzar una cifra de aproximadamente 5800 hectáreas dedicadas a 
diversos cultivos y ganadería de pequeña escala tales como huertas comunitarias, pequeñas huertas para consumo local, explotaciones para autoconsumo y explotaciones mixtas de producción agrícola y ganadera (Erickson, 2004; Gordon \& Scott, 2008).

También se considera fundamental una mayor protección para el medio natural del anillo verde a través de políticas más estrictas para los usos y actividades permitidas dentro de los suelos calificados como núcleo de suelo natural y conectores naturales. Paralelamente, se pone especial atención al tema de la conectividad con la propuesta de trabajar en la conexión del anillo verde con la Red de Ecosistemas de la Capital vinculándolo a paisajes singulares como Carp Hills, South March Highlands y el Bosque de Cumberland o, cruzando el río Ottawa, con tierras protegidas de la ciudad de Gatineau (entre otras, el Parque Gatineau, la Bahía McLaurin o varias reservas agrícolas). Así, se propone la conexión de las sendas del anillo verde con la Red de Sendas de la Capital para proveer a los ciudadanos de un mayor número de áreas recreativas. Para el planeamiento en detalle de la zona, se han creado siete sectores definidos en función de las características del paisaje reconocible y que se encuentran delimitados por los principales condicionantes físicos, tales como carreteras, líneas de ferrocarril, etc. El objetivo es proceder a su fotografía aérea y cartográfica con el fin de aplicar directrices específicas en cada sector, proporcionando un análisis descriptivo de las distintas zonas y orientaciones para su gestión en los próximos diez años. Por todo ello, podemos considerar al anillo verde de Ottawa como uno de los más completos y protegidos del mundo, especialmente gracias a que la mayor parte del suelo es de propiedad pública y a que contiene una amplia diversidad vegetal y faunística (Caldwell \& Temple, 2009).

Entre los desafíos pendientes destacan:

- El logro de una mayor y mejor coordinación entre la política operativa desarrollada por los ayuntamientos, permitiendo la expansión urbana de baja densidad más allá del anillo verde y las líneas estratégicas regionales a alcanzar a largo plazo establecidas por el gobierno federal a través de la NCC, puesto que los gobiernos locales, a menudo, se ven sometidos a numerosas presiones urbanísticas que les han conducido a aprobar propuestas urbanísticas no siempre coherentes con la planificación regional (Kipper, 2021). En este sentido, al anillo verde se le achaca haber contribuido a encarecer los precios de los pisos de la parte central de la ciudad y promover la dispersión de la misma mediante la búsqueda por parte de los ciudadanos de viviendas con precios más asequibles en zonas más alejadas del centro. Y, dado que aproximadamente la mitad del millón de habitantes de Ottawa vive en los suburbios más allá del anillo verde, todo ello supone un mayor coste en la provisión de servicios a los 
ciudadanos suburbanitas y una fuerte dependencia del vehículo privado e incremento de los viajes motorizados (Prentice, 2012). Por ello, se puede considerar que esta iniciativa ha alcanzado un éxito parcial al no lograr contener el crecimiento urbano, como se pretendía originalmente y permitir el fenómeno conocido como leapfrog, el desplazamiento de la expansión urbana más allá de sus límites hacia los municipios del anillo exterior, aunque sí haya logrado proteger ciertos espacios abiertos, sistemas de áreas verdes y tierras de cultivo (Han \& Go, 2019).

- Desde la Coalición del anillo verde (Greenbelt Coalition of Canada's Capital Region, 2010) se le reprocha la falta de compromiso ambiental ante la tala, drenaje y retirada de castores de diferentes humedales y bosques del anillo verde para la ampliación de instalaciones e infraestructuras de transporte. También plantean que, dado el papel fundamental de la agricultura dentro del anillo verde, al representar el 25\% de los usos del suelo, su tratamiento a través de figuras e instrumentos concretos no está bien definido en la revisión del Plan de anillo verde.

\subsection{El Anillo Verde de Ontario}

El anillo verde de Ontario es uno de los de más reciente creación, derivado del esfuerzo realizado por el gobierno de la Provincia de Ontario para hacer frente a la preocupación pública por la rápida urbanización y sus impactos (Amati \& Taylor, 2010). Con una extensión de cerca de 800000 hectáreas, este anillo verde destaca por su dimensión y su alto porcentaje de tierras protegidas, siendo uno de los más grandes y diversos del mundo. En él se ubican la ciudad de Toronto, ciudades y pueblos de tamaño medio, y, núcleos de escasa población, sumando un total de 110 municipios (ver Figura 2). Con una población que supera los 9 millones de personas en la actualidad, se prevé que la región crecerá a 13,48 millones de personas para 2041 (Ministry of Municipal Affairs and Housing, 2020b).

A finales de la década de 1990, el aumento de la concienciación sobre los problemas relacionados con la expansión urbana dio lugar a actuaciones aisladas (protección de Oak Ridges Moraine y creación de iniciativas de crecimiento inteligente), por parte del gobierno conservador en el poder (1995-2003) y a la generación de diversas iniciativas ciudadanas, que impulsarían posteriormente la creación del anillo verde. En el año 2003, el gobierno liberal recién elegido bajo el mandato del primer ministro Dalton McGunity capitalizó el trabajo preliminar establecido por los conservadores, proponiendo la creación de un anillo verde, anunciado como el anillo verde protegido permanentemente más grande del mundo. En 2005, 
la Ley de Anillos Verdes (Greenbelt Act) fue aprobada por el gobierno provincial, lo que permitió la creación de un Plan para el Anillo Verde (Greenbelt Plan), también publicado durante ese mismo año y revisable cada diez años, y la creación de un Consejo Consultivo para asesorar al Ministro de Asuntos Municipales (Allen \& Campsie, 2013).

El Plan para el anillo verde (Greenbelt Plan) aborda múltiples actuaciones como la conservación de la naturaleza y la infraestructura, incluida la agricultura (extensas áreas de tierras agrícolas con cultivos propios de la región), y está diseñado para proteger la pérdida de tierras agrícolas, el patrimonio natural (bosques, humedales, ríos, lagos, etc.), y para mitigar el cambio climático. En la implementación y desarrollo del Plan para el anillo verde participan tanto la Administración como las Organizaciones No Gubernamentales involucradas en el tema. Además, las autoridades municipales deben garantizar que las decisiones y planes aprobados en sus respectivos municipios lo sean de acuerdo a lo establecido en el Plan de anillo verde. Desde el principio, el Plan para el anillo verde fue diseñado para funcionar de forma coordinada con los Planes de Crecimiento urbano (Growth Plans) (Ministry of Municipal Affairs and Housing, 2017). 
Figura 2. Anillo Verde de Ontario
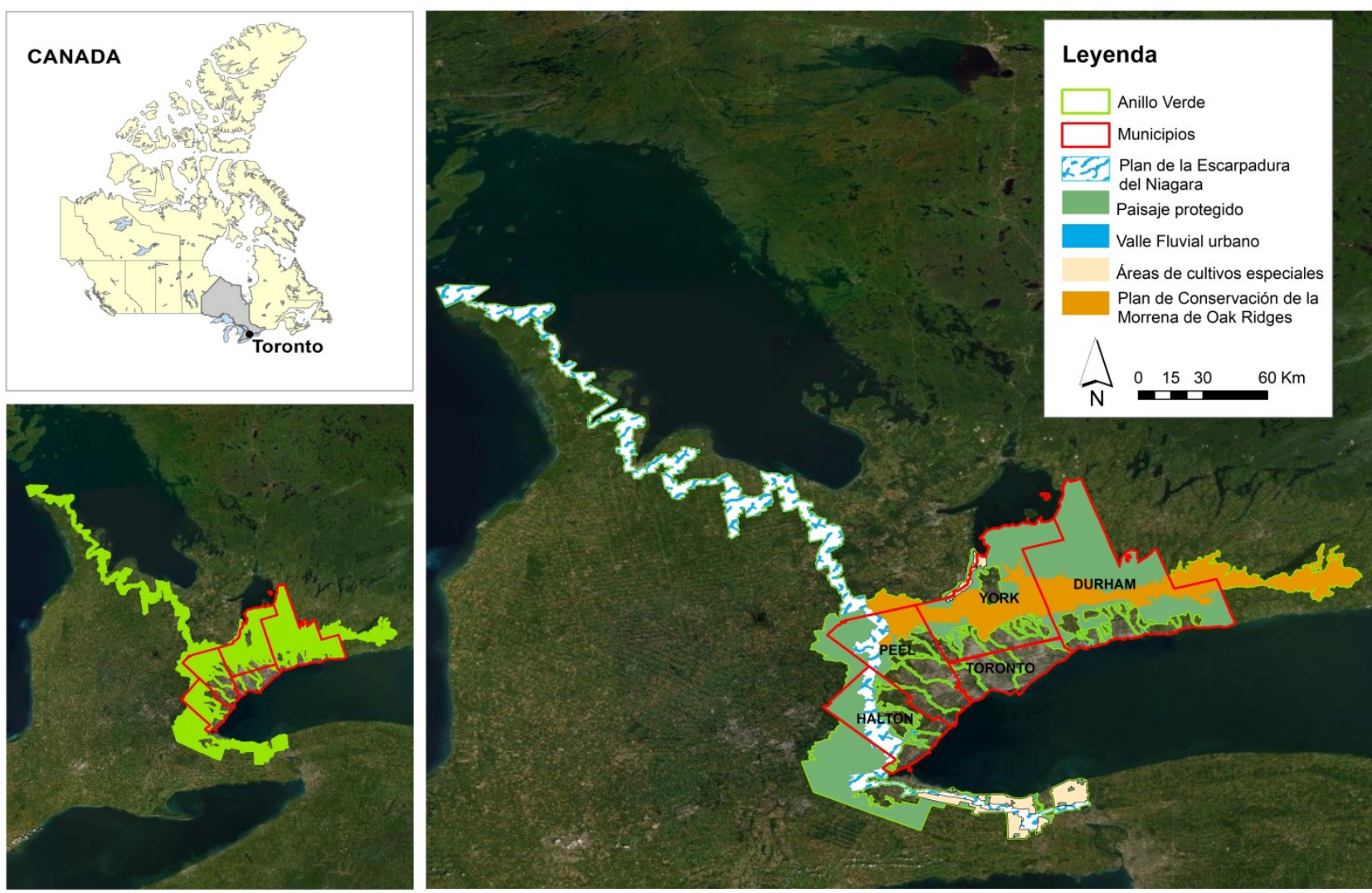

Fuente: elaboración propia a partir de Ontario Ontario Ministry of Northern Development, Mines, Natural Resources and Forestry (2021)

El Plan para el anillo verde anillo identifica dónde no puede urbanizarse con el fin de proteger las tierras agrícolas, mientras que los Planes de Crecimiento urbano deciden cómo y en qué zonas se puede urbanizar. En 2005, la Provincia de Ontario aprobó la Ley de Lugares para Crecer (Places to Grow Act) como base para preparar planes de crecimiento urbano en Ontario. El primero de estos planes, aprobado en 2006, fue para la Región de la Gran Herradura de Oro el (Greater Golden Horseshoe Region). Basado en principios de crecimiento inteligente, este plan de crecimiento urbano fue diseñado para gestionar el crecimiento de la región hasta 2031 (ahora extendido hasta 2041), delinear las proyecciones de población y fomentar la intensificación en 25 centros de crecimiento urbano (Ministry of Municipal Affairs and Housing, 2020a). El personal de la Provincia revisa el Plan del anillo verde y los Planes de Crecimiento urbano cada 10 años, para evaluar su efectividad. Por lo tanto, el anillo verde está fuertemente protegido porque es sólo durante este proceso de revisión cuando el Ministro de Asuntos Municipales y Vivienda puede hacer enmiendas a las áreas protegidas dentro del anillo verde. Sin embargo, tales cambios no pueden disminuir el área total del anillo verde. La Provincia lanzó la primera revisión simultánea del Plan del Anillo Verde, del Plan de Crecimiento de la Gran 
Herradura de Oro (Greater Golden Horseshoe), del Plan Niagara Escarpment y del Plan de Conservación de Moraine Oak Ridges, en 2015. Para la revisión coordinada de estos cuatro planes, la Provincia nombró un panel asesor y sobre las conclusiones de ese panel, se publicaron planes revisados en 2017 (Ministry of Municipal Affairs and Housing, 2020a).

El diseño institucional del Plan para el anillo verde y de los Planes de Crecimiento se basa en una estructura jerárquica vertical que se ajusta al sistema de planificación del uso de la tierra dirigido por la Provincia de Ontario. Por medio de la Ley de Planificación (Planning Act) y de la Declaración de Política Provincial (Provincial Policy Statement), la Provincia proporciona orientación para la planificación del uso de la tierra en Ontario. Dentro de áreas específicas de la Provincia, los planes provinciales tienen políticas más detalladas para cumplir con ciertas metas, como el Plan de Crecimiento de la Gran Herradura de Oro (Greater Golden Horseshoe) y el Plan del anillo verde. A continuación, los municipios deben implementar estas políticas provinciales a través de sus planes oficiales. En casos de disputas relacionadas con decisiones de planificación municipal, se pueden presentar apelaciones ante el Tribunal de Apelación de Planificación Local (Local Planning Appeal Tribuna). Como tribunal administrativo cuasi judicial que toma decisiones sobre asuntos de planificación del uso de la tierra municipal, el Tribunal de Apelación de Planificación Local proporciona una función importante de resolución de disputas en el sistema de planificación del uso de la tierra de Ontario (Macdonald \& Keil, 2012).

En el tiempo transcurrido desde que se creó el anillo verde, ha habido un cambio positivo en el discurso en torno al mismo. De hecho, el anillo verde fue inicialmente polémico desde el punto de vista político y fue impugnado por agricultores, constructores y municipios. Sin embargo, las objeciones iniciales de estos actores han sido reemplazadas por la aceptación, lo que supone un amplio apoyo público al Plan del anillo verde y un cambio positivo hacia una gobernanza más eficaz del anillo verde (Ali, 2008; Deaton \& Vyn, 2015).

El Plan del anillo verde se ha planteado como la mejor política de protección para la zona, pero todavía tiene que enfrentarse a diversos retos, entre los que se pueden señalar los siguientes:

- Las relaciones entre la Provincia y los municipios en Ontario, todavía fuertemente influenciadas por el legado de la legislación del siglo XIX lo que refuerza relaciones de poder desiguales, responsabilidades compartidas y problemas de coordinación que influyen en la implementación de políticas como el Plan del anillo verde. A pesar de las recientes reformas legislativas municipales que han otorgado a los municipios más autonomía, reflejando un enfoque provincial menos prescriptivo, las asimetrías de poder continúan siendo evidentes ya 
que los municipios aún operan en un entorno político incierto, donde los cambios en los intereses provinciales pueden alterar los recursos y responsabilidades locales (Henstra, 2017).

- Las diversas reacciones municipales al Plan del anillo verde, lo que refleja la complejidad de las estructuras municipales existentes en la región de la Gran Herradura de Oro (Greater Golden Horseshoe). Con 110 municipios que incluyen grandes ciudades y comunidades rurales, los municipios de la región tienen diferentes capacidades administrativas y perspectivas de desarrollo. Muchos municipios han adoptado el Plan del anillo verde al perseguir sus propias iniciativas, mientras que otros municipios ven el anillo verde como un "estrangulamiento" debido a las restricciones de uso de la tierra que conlleva que pueden impedir atraer nuevos desarrollos residenciales y obstaculizar la generación de ingresos para dichos municipios. En este sentido, algunos municipios han favorecido nuevas urbanizaciones de baja densidad, creando condiciones que entran en conflicto con la planificación regional, promoviendo la especulación de los terrenos y originando un fuerte descenso del número de agricultores (Carter-Whitney, 2010; Côté \& Fenn, 2014).

- Los impactos de los problemas de coordinación relacionados con la implementación de políticas los experimentan de primera mano los agricultores, ya que son los más directamente afectados por el Plan del anillo verde. Caldwell y Proctor (2013), señalan que los agricultores aprecian los beneficios que ofrece el Plan del anillo verde para proteger las tierras agrícolas, aunque la diversidad de políticas junto con los problemas de coordinación a nivel provincial y municipal crean muchas incertidumbres en los agricultores. Por lo tanto, si bien el Plan del anillo verde proporciona una base excelente para proteger las tierras agrícolas, los agricultores consideran que se necesitan nuevos programas gubernamentales para apoyar la viabilidad económica del sector agrícola y garantizar una agricultura sostenible (Akimowicz et al., 2016).

- La existencia de territorialidades superpuestas y los diferentes alcances espaciales de las numerosas políticas aplicadas en la región de la Gran Herradura de Oro (Greater Golden Horseshoe), han generado una implementación problemática. Algunas políticas están diseñadas para toda la Provincia (la Declaración de Política Provincial), otras para toda la región de la Gran Herradura de Oro (Planes de Crecimiento) y muchas otras en zonas funcionales inferiores a la región de la Gran Herradura de Oro (Plan del anillo verde). Estas jurisdicciones múltiples y parcialmente superpuestas crean problemas de coordinación y conflictos entre los gobiernos en varios niveles y también con el sector privado y la sociedad civil y dificultan el desarrollo de una gestión eficaz del anillo verde. Todo ello, ha permitido, 
por ejemplo, el fenómeno leapfrog, el desplazamiento de la expansión urbana más allá de sus límites hacia los municipios del anillo exterior. El fenómeno leapfrog es problemático porque requiere la construcción de carreteras y autovías a través de vías verdes y tierras agrícolas, lo que aumenta el tráfico, fragmenta áreas naturales, reduce el número de agricultores y socava el enfoque de crecimiento inteligente del Plan. Además, parecen existir indicios de que algunos promotores están comprando tierras agrícolas de forma especulativa más allá del anillo verde con un segmento específico de esta actividad impulsado por empresas extranjeras y fondos de pensiones, que presionan a los propietarios para que vendan sus propiedades, lo que está generando conflictos entre los residentes y la desinversión agrícola (Vyn, 2012). Tampoco se está produciendo una adecuada gestión de las infraestructuras de transporte, lo que está ocasionando impactos ambientales en la escala local y se estima que el desarrollo del Plan del anillo verde está provocando un incremento importante en el precio de la vivienda en el área metropolitana de Toronto (Fung \& Conway, 2007).

Por lo tanto, a pesar de estos retos pendientes y de tratarse de un proyecto con una corta andadura, se puede afirmar que el Plan del anillo verde ha sido eficaz para dirigir el desarrollo urbano hacia las ciudades y lejos de las tierras agrícolas dentro del anillo verde. En esta labor, ha contribuido, en gran medida, la Fundación de Amigos del Anillo Verde (Friends of the Greenbelt Foundation), una organización sin ánimo de lucro, con un fondo inicial de 25 millones de dólares canadienses aportado por el gobierno provincial, creada para promover el anillo verde a través de programas educativos (Ministry of Municipal Affairs and Housing, 2017).

En definitiva, el Plan del anillo verde de Ontario tiene un diseño institucional funcional, con una clara estructura de implementación vertical administrada por la Provincia e implementada por los municipios, que ha generado problemas de coordinación institucional, conflictos de intereses y políticas e impactos no deseados que han dado como resultado un anillo verde desigual.

\subsection{La Reserva de la Biosfera del Anillo Verde de São Paulo}

El anillo verde de São Paulo, con una superficie de 2111432 hectáreas, fue creado en el año 1994. Se impulsó a través del Programa sobre el Hombre y la Biosfera (Man y Biosphere-MaB) de la Unesco, bajo la figura de Reserva de la Biosfera, con el fin de proteger el patrimonio natural y las tierras ambientalmente sensibles. Constituye un ejemplo exitoso de asociacionismo ciudadano, ya que el proceso se promovió gracias a un movimiento popular en la década de los años ochenta. Diferentes Organizaciones No Gubernamentales (ONGs) de carácter medioambiental (OIKOS Uniao dos Defensores da Terra y SOS Mata Atlântica, entre otras), 
consiguieron reunir 150000 firmas para luchar contra la Circunvalación Metropolitana Urbana y aprovecharon ese impulso ciudadano para solicitar la declaración de la zona como Reserva de la Biosfera. El Instituto Forestal, órgano vinculado a la Secretaría de Infraestructura y Medioambiente del Estado de São Paulo encargado de la gestión de la biodiversidad en la región, asumió el liderazgo y, actuando en su función de órgano gestor de la mayoría de las áreas protegidas, fue el responsable de elaborar la documentación técnica y de poner en marcha el proceso que convertiría la zona en Reserva de la Biosfera. Finalmente, en 1994, llegó la declaración por parte de la Unesco de Reserva de la Biosfera para el anillo verde de la ciudad de São Paulo. Esta área, además, forma parte de la Reserva de la Biosfera de la Mata Atlántica, establecida en 1991 y de ámbito interestatal. Las dos reservas son consideradas interdependientes al unirse a través de sus sistemas de gestión, pero mantienen una identidad y enfoque propios (Rodrigues et al., 2006; Moreno-Peñaranda, 2021; Ramos-Ribeiro, 2015).

Las actuaciones desarrolladas en el marco del anillo verde han tratado de abordar la transformación del paisaje causada por la expansión urbana con programas que fomenten la conservación de las características naturales fundamentales y el equilibrio ecológico, así como el patrimonio cultural y los recursos agrícolas. La Reserva de la Biosfera se extiende a lo largo de 73 municipios, incluyendo prácticamente por completo dos áreas metropolitanas (las regiones metropolitanas de São Paulo y de Santos) y parcialmente, las regiones de Sorocaba, São José dos Campos, Registro y Campinas, junto con una variedad de cuencas y subcuencas hidrográficas, numerosas unidades de conservación y superficies cultivadas. Está habitada por cerca de 23 millones de personas (Rodrigues et al., 2006), lo que supone más de un 10\% de la población total del país en un área equivalente a un 2 por mil del territorio brasileño. Además, la Reserva engloba más de 6000 kilómetros cuadrados de selva y otros ecosistemas de bosque atlántico, siendo uno de los biotopos más amenazados del planeta (ver Figura 3). 
Figura 3. Reserva de la Biosfera del Cinturón Verde de la ciudad de São Paulo
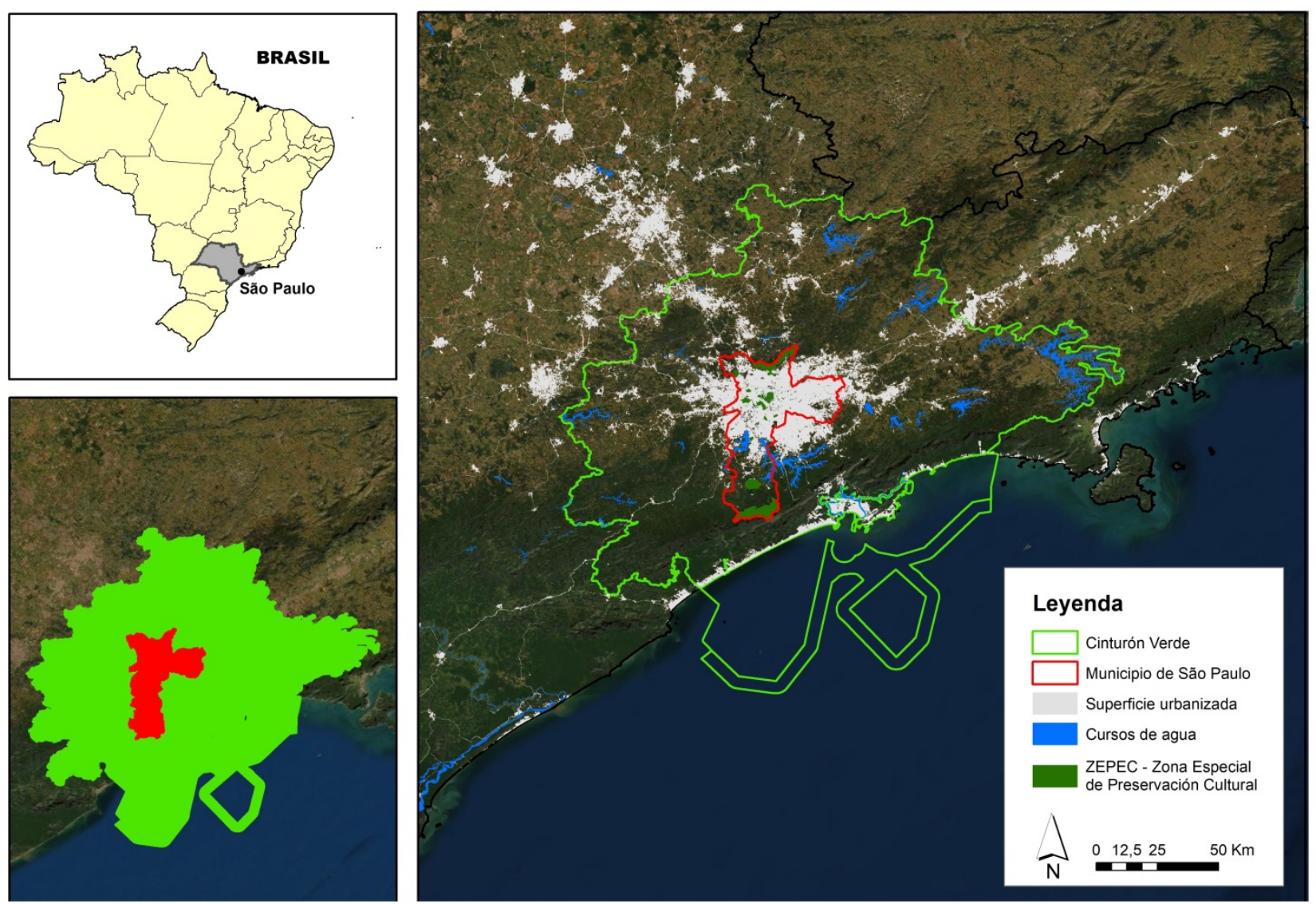

Fuente: elaboración propia a partir de Instituto Florestal - IF/SMA (2021)

Debido a su espectacular diversidad biológica, la Reserva de la Biosfera del anillo verde presta valiosos servicios ecosistémicos y representa una oportunidad excelente para una gestión integrada de las ciudades y de los ecosistemas de la región, complementaria a los procedimientos tradicionales de gestión territorial. Por ello, para la definición de sus límites, se tuvieron en cuenta aspectos relativos al metabolismo sistémico del área metropolitana, considerando las desequilibradas relaciones de intercambio que se producían entre el anillo verde y los pueblos que se encuentran en sus proximidades. El objetivo de la Reserva de la Biosfera del anillo verde es conseguir un mayor equilibrio en esas relaciones de intercambio asegurando la conservación de la biodiversidad y el bienestar de su población, armonizando la relación entre el área natural y urbana y disminuyendo la presión en la ciudad y sus alrededores (Rodrigues et al., 2006; Moreno-Peñaranda, 2021).

Hay que destacar que se trata de un caso de importancia internacional debido a la escasez mundial de modelos de gestión para áreas ambientalmente sensibles sometidas a fuertes presiones, como es el caso de Reserva de la Biosfera del anillo verde. Su prioridad es servir de 
laboratorio de acciones y propuestas para la Red Mundial de Reservas de Biosfera, pero sentando las bases en la construcción de un modelo de gestión basado en su propia experiencia. Este sistema se apoya en una estructura formada por dos órganos: 1) El Consejo de Gestión, cuya misión es proponer y ayudar en la gestión de la Reserva y convertirse en un foro capaz de incorporar las propuestas de todos los segmentos de la sociedad, promoviendo una gestión participativa en cumplimiento de lo establecido por el Programa MaB de la Unesco; y 2) La Secretaría, dependiente del Instituto Forestal de São Paulo y que actúa como agencia ejecutiva para la Reserva, cuya función es la de proponer y llevar a cabo programas y proyectos en la zona y dar asistencia al Consejo (Moraes Victor et al., 2004). Más en detalle, el Consejo de Gestión, haciéndose eco de las premisas del Programa MaB de la Unesco, busca promover la gestión participativa e incluye entre sus miembros representantes gubernamentales y pertenecientes a los distintos niveles administrativos (municipal, estatal y federal) y representantes de la sociedad civil, comunidad científica y agentes privados. Por último, la Secretaría propone y ejecuta los programas y proyectos dentro del ámbito de la Reserva de la Biosfera del anillo verde. Su principal instrumento es el Plan de Acción de la Reserva de la Biosfera del anillo verde, donde propone orientaciones sobre las actividades a realizar en la misma. Este sistema de gestión permite que lleguen demandas ciudadanas al Consejo que reflejan los conflictos existentes tanto en el ámbito municipal como regional y el Consejo posibilita la mediación de dichos conflictos (Rodrigues et al., 2007). Esto es de gran utilidad teniendo en cuenta que, aunque sea el Instituto Forestal el principal gestor de la Reserva de la Biosfera del anillo verde de São Paulo, los ayuntamientos tienen autonomía para la ordenación del suelo y son los que desarrollan los Planes de Manejo, con lo que pueden surgir conflictos derivados, por ejemplo, de la determinación de los niveles de protección de los usos del suelo. Además, se cuenta también con el papel supervisor de la Unesco y de otros organismos internacionales que colaboran con ayudas financieras. Un reto pendiente es el de implicar en la gestión a la iniciativa privada y a la sociedad civil, puesto que éstos tienen solamente una representación simbólica en el Consejo de Gestión.

En cuanto a las actuaciones desarrolladas en la escala operativa, destaca el apoyo al Programa de los Jóvenes. El Programa de los Jóvenes surgió en 1993 con el fin de combatir la exclusión social y el aumento del tráfico de drogas en el entorno urbano de São Paulo, donde los jóvenes de bajos ingresos y con pocas perspectivas de mejora en su cualificación se convertían en presas fáciles para las actividades ilegales y la violencia. Ante este panorama, la Reserva de la Biosfera del anillo verde, a partir de 1994, puso en marcha iniciativas capaces de integrar la 
conservación y recuperación del medio ambiente con los programas y acciones para combatir la pobreza y garantizar el bienestar de la población en riesgo de exclusión social, mediante acciones centradas en la educación juvenil, la cualificación y la formación de profesionales de cara a garantizar la conservación y el uso sostenible de los recursos naturales (Rodrigues, 2018).

El apoyo al Programa de los Jóvenes es una propuesta innovadora de intervención socioambiental coordinada por el Instituto Forestal en cooperación con otras instituciones tales como los grupos ecologistas, los gobiernos locales, la iniciativa privada, las universidades, voluntarios, etc. Está estructurada a través de un conjunto de instrumentos legales e inició su andadura a través de un proyecto piloto financiado por la Unesco en São Roque. Las actividades que plantean son: la conservación y recuperación del anillo verde, la concienciación sobre el medio ambiente, la capacitación técnica de los jóvenes en actividades agroforestales y otros tipos de trabajos relacionados con el reciclaje, el turismo ecológico, la vigilancia del medio ambiente y la generación de nuevas posibilidades de empleo mediante la promoción de "eco-trabajos" y la difusión de nuevas tecnologías aplicables al concepto de desarrollo sostenible (Rodrigues et al., 2006). Destaca también, un programa de Agricultura Limpia (Agricultura Limpa) lanzado por la Secretaría de Agricultura y abastecimiento de la ciudad de São Paulo que pretende fomentar una agricultura ecológica en tierras agrícolas pertenecientes al anillo verde (Lemes de Oliveira, 2019).

La Reserva de Biosfera del anillo verde realiza también una serie de funciones ecosistémicas de gran relevancia como son, entre otras, la regulación climática, la provisión de agua para 19 millones de personas, la minimización de inundaciones, la lucha contra la erosión, la conservación de la biodiversidad, el incremento de la seguridad alimentaria, la captación de $\mathrm{CO}_{2}$, la reducción de diversos contaminantes del aire y la provisión de servicios culturales. Sin embargo, la realización de esas funciones ecosistémicas, se enfrenta a grandes amenazas, entre las que destacan la especulación inmobiliaria, como consecuencia del rápido crecimiento urbano que está experimentando el área metropolitana de São Paulo, o la posible percepción del desarrollo de iniciativas ecológicas como un obstáculo que dificulta el crecimiento en una economía emergente como la brasileña. En este sentido, la delimitación de la Reserva de la Biosfera tuvo en cuenta los aspectos sistémicos del metabolismo metropolitano, tratando de implantar un modelo sostenible para la gestión de los ecosistemas periurbanos sometidos a las fuertes presiones de las áreas urbanizadas. Como consecuencia de ello, se plantearon unas unidades de conservación estatales de protección integral que están constituidas por doce 
parques, dos reservas y una estación ecológica y 25 áreas protegidas como patrimonio cultural y arquitectónico.

La Reserva de Biosfera del anillo verde persigue alcanzar cambios profundos en los patrones de desarrollo y en el estilo de vida de las personas de la región. No obstante, debido al contexto socioeconómico en el que se ubica, tiene que hacer frente a dos desafíos importantes: por un lado, los altos niveles de exclusión social y pobreza derivados de la creciente polarización económica y, por otro lado, el intenso proceso de degradación ambiental debido a las fuertes presiones urbanísticas propias de un país emergente. De hecho, el mayor reto es precisamente la integración adecuada de estos dos desafíos, ya que gran parte de las áreas con mayor valor ecológico de la Reserva de la Biosfera se encuentran localizadas en espacios periféricos del área metropolitana que se corresponden con zonas de altos niveles de exclusión social (MorenoPeñaranda, 2021). De ahí, la importancia que los modelos de intervención socio-ambiental, como el Programa de Jóvenes - Medio Ambiente e Integración Social (PJ-MAIS), están adquiriendo al combinar la protección de jóvenes en riesgo de exclusión social con actuaciones de preservación y recuperación ambiental.

Por último, debe señalarse que, a pesar de la amplia extensión de superficie incluida bajo la denominación de Reserva de la Biosfera, tan sólo una pequeña porción del suelo de la misma está cubierta con figuras de protección especial, puesto que únicamente 220422 hectáreas se encuentran bajo la designación de Conservación y en torno a 50000 hectáreas bajo la denominación de uso sostenible. Esto limita la capacidad de actuación del Instituto Forestal, al no disponer de las competencias sobre la gestión del suelo y tener que limitarse a aportar recomendaciones en cuanto a la gestión de dichos suelos.

\section{Análisis comparativo y discusión}

En esta sección se realiza un análisis comparativo de los tres casos de estudio que hemos seleccionado: (1) el anillo verde de Ottawa, (2) el anillo verde de Ontario y (3) la Reserva de la Biosfera del anillo verde de São Paulo, centrándonos, de acuerdo con Bartesaghi Koc et al. (2017), en aspectos tales como la forma, las funciones, los usos del suelo, el hábitat, las áreas y espacios con alto valor ecológico e interés, además del año de constitución, la escala, la superficie y el enfoque de gestión (véase Tabla 2), contrastando los resultados obtenidos con la literatura previa. Alguno de los casos analizados, como el anillo verde de Ottawa, tiene ya una larga trayectoria al ser de 1956, mientras que los otros dos casos son mucho más recientes (2005 en Ontario y 1994 en São Paulo), aunque todos fueron diseñados con el objetivo 
primigenio de contener el crecimiento urbano y mantener la separación entre la ciudad y el campo (Taylor, 2019).

Respecto a la escala, cuestión relevante a considerar en el diseño de estos instrumentos, se puede señalar que, aunque en los primeros anillos verdes puestos en marcha a principios del siglo XX la escala tendía a ser municipal, a medida que la escala territorial de estos espacios ha ido aumentando, la regulación, gestión y coordinación se han vuelto más complejas al involucrar a distintos niveles de gobierno, a diversas políticas y a un mayor número de municipios (Baxendale \& Buzai, 2019; Monclús, 2018). En los tres casos estudiados la escala es metropolitana, por lo que las complejidades institucionales y los desafíos de gestión son elevados, requiriendo una importante coordinación entre los gobiernos, en varios niveles, las diversas actuaciones políticas y con los otros actores públicos, privados y de la sociedad civil (Macdonald et al., 2021). Además, en el caso de la Reserva de la Biosfera del anillo verde de São Paulo, hay que tener en cuenta, además, el apoyo internacional, apoyo que resultó fundamental para la puesta en marcha de esta iniciativa.

Tabla 2. Análisis comparativo de los tres estudios de caso seleccionados

\begin{tabular}{|c|c|c|c|}
\hline & Ottawa (Canadá) & Ontario (Canadá) & São Paulo (Brasil) \\
\hline Año & 1956 & 2005 & 1994 \\
\hline Escala & Metropolitana & Metropolitana & Metropolitana \\
\hline Superficie & $20000 \mathrm{Ha}$. & $800000 \mathrm{Ha}$ & $2111432 \mathrm{Ha}$. \\
\hline Forma & $\begin{array}{l}\text { Cuñas Verdes y vías } \\
\text { verdes que adoptan una } \\
\text { forma perimetral }\end{array}$ & $\begin{array}{c}\text { Un Anillo Verde } \\
\text { semicircular junto con un } \\
\text { corredor fluvial y vías } \\
\text { verdes }\end{array}$ & $\begin{array}{l}\text { Anillo Verde } \\
\text { radio-concéntrico en torno } \\
\text { al municipio de Sao Paulo }\end{array}$ \\
\hline Funciones & $\begin{array}{c}\text { Contención de la } \\
\text { dispersión urbana. } \\
\text { Favorecer la movilidad } \\
\text { urbana. } \\
\text { Dotación de áreas verdes. } \\
\text { Reserva de suelo para } \\
\text { infraestructuras y } \\
\text { equipamientos públicos. } \\
\text { Potenciación de la } \\
\text { agricultura de } \\
\text { proximidad, ecológica y } \\
\text { sostenible. } \\
\text { Usos recreativos y } \\
\text { turísticos. } \\
\text { Fomento de la economía } \\
\text { local. }\end{array}$ & $\begin{array}{c}\text { Protección de las tierras } \\
\text { agrícolas y de espacios } \\
\text { naturales. } \\
\text { Contención de la } \\
\text { dispersión urbana. } \\
\text { Contención del } \\
\text { crecimiento. } \\
\text { Organización del sistema } \\
\text { verde urbano. } \\
\text { Usos recreativos y } \\
\text { turísticos. } \\
\text { Preservación de las } \\
\text { características ecológicas. } \\
\text { Mejorar la resiliencia } \\
\text { climática. } \\
\text { Promoción del desarrollo } \\
\text { económico. }\end{array}$ & $\begin{array}{c}\text { Protección del medio } \\
\text { rural. } \\
\text { Contención del } \\
\text { crecimiento urbano. } \\
\text { Conservación de áreas } \\
\text { naturales. } \\
\text { Usos recreativos, } \\
\text { formativos y culturales. } \\
\text { Fomento de la agricultura } \\
\text { ecológica y sostenible. } \\
\text { Desarrollo de actividades } \\
\text { de economía verde. }\end{array}$ \\
\hline
\end{tabular}


Tabla 2. Continuación

\begin{tabular}{|c|c|c|c|}
\hline & Ottawa (Canadá) & Ontario (Canadá) & São Paulo (Brasil) \\
\hline Usos del suelo & $\begin{array}{c}\text { Agrario. } \\
\text { Natural. } \\
\text { Uso académico } \\
\text { Infraestructuras de } \\
\text { transporte. } \\
\text { Uso terciario. }\end{array}$ & $\begin{array}{c}\text { Natural (humedales, } \\
\text { praderas y bosques). } \\
\text { Residencial. } \\
\text { Agrario. }\end{array}$ & $\begin{array}{c}\text { Residencial. } \\
\text { Natural tipo bosque. } \\
\text { Uso agrario. } \\
\text { Infraestructuras de } \\
\text { transporte. }\end{array}$ \\
\hline Hábitat & $\begin{array}{c}\text { Duna. } \\
\text { Humedal. } \\
\text { Bosque (conífera en la } \\
\text { gran mayoría). } \\
\text { Ribera. }\end{array}$ & $\begin{array}{l}\text { Lago, humedal. } \\
\text { Ribera y valles. } \\
\text { Pradera. } \\
\text { Pasto alto. } \\
\text { Bosque. }\end{array}$ & $\begin{array}{c}\text { Bosques ombrófilos. } \\
\text { Selva tropical atlántica } \\
\text { brasileña. } \\
\text { Sierra de Cantareira. } \\
\text { Sierra del mar. } \\
\text { Costa. } \\
\text { Pradera. } \\
\text { Ecosistemas marinos. }\end{array}$ \\
\hline $\begin{array}{l}\text { Áreas con alto } \\
\text { valor ecológico } \\
\text { y espacios de } \\
\text { interés }\end{array}$ & $\begin{array}{c}\text { Stony Swamp } \\
\text { Old Quarry Trail } \\
\text { Log Farm } \\
\text { Carlsbad Springs } \\
\text { Pinhey Forest } \\
\text { Pine Grove } \\
\text { Green's Creek } \\
\text { Mer Bleue (red Ramsar) } \\
\text { Shirleys Bay }\end{array}$ & $\begin{array}{l}\text { Oak Ridges Moraine } \\
\text { Lago Ontario } \\
\text { Niagara } \\
\text { Bruce peninsula } \\
\text { Lago Simcoe } \\
\text { Península de Niagara } \\
\text { The Holland Marsh } \\
\text { Carolinian life zone }\end{array}$ & $\begin{array}{l}\text { Parques estatales Albert } \\
\text { Löfgren, Jurupurá, } \\
\text { Jaraguá, Juquery, } \\
\text { Cantareira y Serra do Mar } \\
\text { Reserva Forestal del } \\
\text { Morro Grande } \\
\text { Estación Ecológica de } \\
\text { Itapeti. }\end{array}$ \\
\hline $\begin{array}{l}\text { Enfoque de } \\
\text { gestión }\end{array}$ & $\begin{array}{c}\text { Sistema de gestión } \\
\text { vertical (de arriba hacia } \\
\text { abajo) liderado por el } \\
\text { gobierno federal a través } \\
\text { de la Comisión de la } \\
\text { Capital Nacional (NCC) } \\
\text { que marca las líneas } \\
\text { estratégicas y la política } \\
\text { operativa desarrollada por } \\
\text { los municipios, } \\
\text { generándose problemas } \\
\text { de coordinación. }\end{array}$ & $\begin{array}{c}\text { Sistema de gestión } \\
\text { vertical (de arriba hacia } \\
\text { abajo) administrado por el } \\
\text { gobierno provincial } \\
\text { e implementado por los } \\
\text { municipios, que genera } \\
\text { asimetrías de poder y } \\
\text { problemas de } \\
\text { coordinación institucional } \\
\text { y conflictos de políticas. }\end{array}$ & $\begin{array}{c}\text { Sistema de gestión } \\
\text { vertical (de arriba hacia } \\
\text { abajo) liderado por el } \\
\text { Instituto Forestal, pero } \\
\text { donde cada municipio } \\
\text { desarrolla sus propios } \\
\text { Planes de Manejo y no } \\
\text { cuentan con una } \\
\text { planificación estratégica, } \\
\text { lo que lleva a que la } \\
\text { implementación sea } \\
\text { desigual y fragmentada. }\end{array}$ \\
\hline
\end{tabular}

Fuente: elaboración propia

Dependiendo de las leyes de planificación del uso de la tierra, puede haber una amplia variedad de regulaciones de planificación, como zonas o designaciones, para proteger los espacios verdes, lo que da como resultado la diversidad de formas espaciales de anillos verdes y objetivos de políticas que se ven a nivel internacional (Taylor, 2019). Además, la forma también condiciona la conectividad de los espacios. En el caso del anillo verde de Ottawa, su diseño en forma de cuñas verdes ha evolucionado hacia una red interconectada de espacios verdes, incluyendo tierras agrícolas orientadas a una agricultura orgánica y sostenible (Campbell, 2019). En el caso del anillo verde de Ontario se conectan a través de vías verdes el Lago 
Ontario con las Cataratas del Niágara y con Oak Ridges Moraine, tratando de interrelacionar diversos ecosistemas vulnerables para una mejor conservación de los mismos (Ali, 2008). Por último, en el caso de la Reserva de la Biosfera del anillo verde de São Paulo, su diseño en forma de anillo verde radio-concéntrico en torno al municipio de São Paulo no favorece la interconexión de las diferentes zonas verdes ni favorece la interconectividad en la región, ya que el tratamiento de las distintas unidades de conservación se realiza a través de Planes de Manejo independientes (Moraes Victor et al., 2004; Moreno-Peñaranda, 2021; Rodrigues et al. 2007).

En lo que se refiere a las funciones, se constata que los tres casos analizados realizan las tres principales que, de acuerdo con la literatura (Amati \& Taylor, 2010; Ahern, 2007; Bengston \& Youn, 2006, Kühn, 2003) este tipo de iniciativas suele perseguir: 1) promover un desarrollo urbano más compacto, con el consiguiente ahorro fiscal en la dotación de servicios e infraestructuras públicas, 2) la protección de las tierras agrícolas y de los espacios naturales y 3) la provisión de servicios ecosistémicos a la ciudad, tales como la purificación del aire, el control de inundaciones, la preservación de la fauna y el hábitat, la mitigación del efecto isla de calor, etc. Sin embargo, con el transcurso del tiempo, estas iniciativas han ido incorporando nuevas funciones y servicios y han tendido a perseguir objetivos de política más ambiciosos que los iniciales, mediante la aplicación de principios de crecimiento inteligente y sostenible y la contribución al desarrollo económico de la región (Amati \& Taylor, 2010; Gordon \& Scott, 2008; Hansen \& Pauleit, 2014; Opdam et al., 2006; Sturzaker \& Mell, 2017; Tzoulas et al., 2007; Young et al., 2014). Así ocurre, en mayor o menor medida, en los tres casos seleccionados, donde en los últimos años se han ampliado los servicios ecosistémicos ofrecidos mediante la salvaguarda de unos espacios naturales privilegiados para el disfrute de la ciudadanía y como lugar para el desarrollo de actividades deportivas, culturales y de ocio y se ha contribuido a la sensibilización y educación ambiental, especialmente en el caso de la Reserva de la Biosfera del anillo verde de São Paulo, en la que se vienen desarrollando distintos proyectos de formación para el empleo sostenible. Por su parte, en el caso de Ottawa, se ha incidido más en la potenciación de los recursos turísticos de la zona para la atracción de visitantes y en el fomento de la economía local, mientras que en Ontario se ha enfatizado la promoción del desarrollo económico y la mejora de la resiliencia climática. Estas iniciativas también se han propuesto controlar el crecimiento disperso, aunque en ninguna de ellas se ha logrado. En los casos de Ottawa y Ontario, la creciente presión urbanística, uno de los principales problemas a los que se enfrentan, ha generado el efecto leapfrog (Deaton \& Vyn, 2015; Fung \& Conway, 2007; Keil \& Macdonald 2016; Macdonald et al., 2021). 
En los tres casos analizados, se observa un uso mixto del suelo. La gestión del uso de estos espacios se erige como un elemento clave para su conservación, puesto que un uso excesivo de los mismos puede entrar en conflicto con la conservación de la biodiversidad y de los usos agrícolas, por lo que el desarrollo de programas específicos para potenciar la agricultura de proximidad, como en Ottawa y Sao Paulo, puede resultar fundamental (por ejemplo, la creación de mercados de venta de productos locales, ayudas para transformar la actividad en agricultura ecológica, la creación de huertas públicas dedicados a crear empleo con fines de inserción social de determinados colectivos o simplemente como una actividad programada de ocio, etc.) (Akimowicz et al., 2016).

Respecto al enfoque de gestión, cabe señalar que en los dos casos canadienses la política que fomenta el anillo verde se encuadra en un marco institucional funcional (Pond, 2009a) y cuenta con sendos planes estratégicos. No obstante, el diseño institucional vertical de las políticas del anillo verde, administradas por un gobierno de nivel superior y luego implementadas por niveles de gobierno inferiores abarcando diferentes actuaciones políticas y jurisdicciones municipales, ha supuesto enormes desafíos de gestión, al generarse problemas de coordinación institucional y conflictos de intereses y políticas, que han afectado a la eficacia de la gobernanza de dichas iniciativas verdes (Han \& Go, 2019; Macdonald et al., 2021). Por su parte, en el caso brasileño, aunque existe un plan de gestión, cada municipalidad desarrolla sus propios Planes de Manejo y no cuentan con una planificación estratégica, lo que lleva a que la implementación sea desigual y fragmentada. Esto puede ser un obstáculo para el desarrollo de una política integrada en la Reserva de la Biosfera del anillo verde de São Paulo (Rodrigues et al., 2007; Monteiro et al., 2020). En esta línea, se han realizado esfuerzos de gestión colaborativa a través del Consejo de gestión de la Reserva de la Biosfera. Además, parece claro que el apoyo ciudadano y la colaboración público-privada son factores de impulso importantes para estas prácticas. En este sentido, estas iniciativas deben ser percibidas por los residentes como una parte importante de la trama urbana que contribuya positivamente a su bienestar social, psicológico y cognitivo (Taylor, 2019). Se trata de que la ciudadanía las perciba como una respuesta innovadora ante los retos ambientales urbanos. Esta implicación ciudadana se puede percibir en Ottawa y en Ontario (Han \& Go, 2019; Deaton \& Vyn, 2015). En el caso de Sao Paulo, se observa que parte de su estancamiento se puede deber a no haber conseguido que la población haga suyo el proyecto (Lemes de Oliveira, 2019; Rodrigues, 2018).

En comparación con las otras dos experiencias analizadas, São Paulo se enfrenta a retos más complejos como consecuencia de las mayores desigualdades sociales existentes. En este 
sentido, se considera muy positivo el trabajo realizado a través de iniciativas de formación en actividades de agricultura y turismo sostenible destinadas a jóvenes, intentando combinar la dimensión social y la dimensión medioambiental en busca de un desarrollo más sostenible. Se está fomentando también una agricultura ecológica y se han creado agrupaciones de agricultores con el fin de desarrollar programas de certificación de la producción de alimentos orgánicos, buscando establecer relaciones de venta directa a los restaurantes de la ciudad. Igualmente, el Instituto Forestal ha puesto en marcha un proyecto de mercado voluntario de neutralización del carbono para apoyar la reforestación (Moreno-Peñaranda, 2021; Ramos-Ribeiro, 2015).

En la siguiente tabla (véase Tabla 3), se recoge, a modo de síntesis, el análisis DAFO (Debilidades-Amenazas-Fortalezas-Oportunidades) de cada caso.

\section{Tabla 3. Análisis DAFO de los tres estudios de caso seleccionados}

\begin{tabular}{|c|c|c|c|}
\hline & Ottawa (Canadá) & Ontario (Canadá) & São Paulo (Brasil) \\
\hline Debilidades & $\begin{array}{c}\text { No existe protección } \\
\text { específica para los paisajes } \\
\text { agrícolas. } \\
\text { Relajación en la limitación a } \\
\text { la hora de urbanizar. } \\
\text { Cierto grado de } \\
\text { discrecionalidad en las } \\
\text { decisiones políticas que } \\
\text { permiten algunos } \\
\text { desarrollos urbanos y otros } \\
\text { no. } \\
\text { Encarecimiento de las } \\
\text { viviendas en las ciudades. }\end{array}$ & $\begin{array}{c}\text { Medidas poco restrictivas } \\
\text { frente a futuros desarrollos } \\
\text { urbanísticos. } \\
\text { Devaluación de los precios } \\
\text { de las tierras agrícolas. } \\
\text { Existencia de multiplicidad } \\
\text { de planes y legislación (El } \\
\text { plan A Place to Grow, el } \\
\text { Plan del Anillo Verde, el } \\
\text { Plan de Conservación Oak } \\
\text { Ridges Moraine, el Plan } \\
\text { Niagara Escarpment, la Ley } \\
\text { de Agua Limpia y la Ley } \\
\text { del Patrimonio de Ontario) } \\
\text { que afectan al área del } \\
\text { Anillo Verde y que } \\
\text { dispersan los recursos } \\
\text { presupuestarios y técnicos } \\
\text { y pueden llevar a } \\
\text { solapamientos y/o } \\
\text { conflictos. } \\
\text { Desigual respuesta por } \\
\text { parte de los municipios } \\
\text { que responde a la } \\
\text { diversidad de contextos y } \\
\text { capacidades de los } \\
\text { mismos. }\end{array}$ & $\begin{array}{l}\text { Aunque surge a raíz de la } \\
\text { iniciativa ciudadana, poca } \\
\text { implicación posterior de la } \\
\text { ciudadanía y de los actores } \\
\text { privados. } \\
\text { Aunque cuenta con un plan de } \\
\text { gestión no dispone de un plan } \\
\text { estratégico ni de una visión a } \\
\quad \text { futuro. } \\
\text { Degradación ambiental y alto } \\
\text { grado de exclusión social en } \\
\text { áreas de gran valor naturalístico. }\end{array}$ \\
\hline
\end{tabular}




\begin{tabular}{|c|c|c|c|}
\hline Amenazas & $\begin{array}{c}\text { Presión urbanística. } \\
\text { Desarrollos urbanos de } \\
\text { baja densidad. } \\
\text { Existencia de un proyecto } \\
\text { de ley de vivienda que } \\
\text { fomentaría los desarrollos } \\
\text { urbanísticos. } \\
\text { Alta concentración de } \\
\text { suelo de uso residencial } \\
\text { disponible en manos de } \\
\text { unos pocos agentes } \\
\text { privados que pueden } \\
\text { controlar los precios. }\end{array}$ & $\begin{array}{l}\text { Fuerte presión urbanística. } \\
\text { Creciente número de } \\
\text { infraestructuras de transporte. } \\
\text { Oposición de algunos } \\
\text { agricultores. } \\
\text { Existencia de una serie de } \\
\text { acuíferos de gran } \\
\text { vulnerabilidad frente a la } \\
\text { contaminación en el área de } \\
\text { Oak Ridges Moraine. }\end{array}$ & $\begin{array}{c}\text { Presión urbanística. } \\
\text { Construcción de infraestructuras. } \\
\text { Existencia de actividades mineras } \\
\text { en la zona. } \\
\text { Actividades de extracción ilegal } \\
\text { de recursos forestales. } \\
\text { Ocupación de tierras } \\
\text { pertenecientes al Anillo Verde } \\
\text { por asentamientos ilegales que } \\
\text { se ha visto incrementada por la } \\
\text { construcción de algunas } \\
\text { carreteras. } \\
\text { La construcción del tramo norte } \\
\text { de la carretera de Rodoanel aisló } \\
\text { algunas zonas de áreas de la } \\
\text { Mata Atlántica, muy cercanas a } \\
\text { áreas de ocupación irregular, lo } \\
\text { que puede incrementar el } \\
\text { cambio de uso de estos terrenos. }\end{array}$ \\
\hline Fortalezas & $\begin{array}{c}\text { Gestión en coherencia } \\
\text { con la movilidad. } \\
\text { Dispone de una } \\
\text { planificación estratégica. } \\
\text { Propiedad pública de la } \\
\text { tierra que permite una } \\
\text { gestión más coherente. } \\
\text { Alto grado de implicación } \\
\text { de organizaciones } \\
\text { científicas } \\
\text { La articulación de planes } \\
\text { de diseño comunitario que } \\
\text { incorporan la visión de las } \\
\text { comunidades locales y } \\
\text { que, aunque no sean } \\
\text { vinculantes, sirven de base } \\
\text { para los Planes de } \\
\text { ordenación. }\end{array}$ & $\begin{array}{c}\text { Impulso de la participación } \\
\text { ciudadana. } \\
\text { Permeabilidad de la zona } \\
\text { verde. } \\
\text { Proximidad y alta } \\
\text { frecuentación del Anillo } \\
\text { Verde interior. } \\
\text { Liderazgo ejercido por la } \\
\text { Greenbelt Foundation. } \\
\text { Gran extensión de superficie } \\
\text { protegida. } \\
\text { Existencia de una legislación } \\
\text { provincial de ordenación } \\
\text { territorial que otorga una alta } \\
\text { protección frente a los } \\
\text { cambios de uso de suelo. } \\
\text { Establecimiento de una visión } \\
\text { estratégica a través de un } \\
\text { Plan específico del Anillo } \\
\text { Verde. } \\
\text { Protección frente al } \\
\text { crecimiento disperso gracias } \\
\text { a las limitaciones en el } \\
\text { crecimiento y al } \\
\text { establecimiento de estándares } \\
\text { en los núcleos dentro del } \\
\text { anillo verde y en los núcleos } \\
\text { rurales. } \\
\text { La inclusión del área del } \\
\text { Niagara Escarpment, una } \\
\text { Reserva de la Biosfera de la } \\
\text { Unesco, dentro del Anillo } \\
\text { Verde para otorgar una } \\
\text { protección mayor a un área } \\
\text { de alto valor ecológico. }\end{array}$ & $\begin{array}{c}\text { Buena preservación de los usos } \\
\text { agrícolas. } \\
\text { Alta protección del suelo. } \\
\text { Puesta en marcha de actividades } \\
\text { orientadas a la creación de } \\
\text { empleo. } \\
\text { Existencia de distintas categorías } \\
\text { de protección (ambiental, } \\
\text { cultural, histórica, artística- } \\
\text { paisajística e indígena), que } \\
\text { permiten considerar las } \\
\text { especificidades de cada zona. } \\
\text { Tendencia a la colaboración } \\
\text { entre instituciones públicas } \\
\text { estatales y municipales } \\
\text { encargadas de la gestión de los } \\
\text { diferentes tipos de unidades que } \\
\text { integran la Reserva (educación } \\
\text { ambiental, fiscalidad, control de } \\
\text { uso, etc.). }\end{array}$ \\
\hline
\end{tabular}


Tabla 3. Continuación

\begin{tabular}{|c|c|c|c|}
\hline & Ottawa (Canadá) & Ontario (Canadá) & São Paulo (Brasil) \\
\hline Oportunidades & $\begin{array}{c}\text { Su flexibilidad para } \\
\text { adaptarse al crecimiento } \\
\text { de la ciudad. } \\
\text { El alto nivel de } \\
\text { conservación de la } \\
\text { biodiversidad y la riqueza } \\
\text { de paisajes. } \\
\text { Alto grado de } \\
\text { concienciación ambiental } \\
\text { de la población. } \\
\text { Posibilidad de desarrollo } \\
\text { de proyectos de } \\
\text { investigación científica en } \\
\text { el área. } \\
\text { Propuesta de ampliación } \\
\text { del Anillo Verde existente } \\
\text { con un segundo anillo el } \\
\text { Gold Belt conformado por } \\
\text { tierras agrícolas. }\end{array}$ & $\begin{array}{c}\text { Posibilidad de unir ambos } \\
\text { Anillos con sistemas } \\
\text { naturales de la región. } \\
\text { La recuperación del anillo } \\
\text { verde exterior como } \\
\text { parque recreativo y de } \\
\text { ocio. } \\
\text { Alto aprovechamiento de } \\
\text { los servicios ecosistémicos. } \\
\text { Alta productividad agrícola } \\
\text { de las tierras del anillo } \\
\text { verde. } \\
\text { Fomento de la movilidad } \\
\text { activa como atracción } \\
\text { turística ampliando rutas de } \\
\text { largo recorrido de carriles } \\
\text { para bicicleta como } \\
\text { la Greenbelt Route o } \\
\text { desarrollando las sendas e } \\
\text { itinerarios } \\
\text { Greenhelt Walks trails }\end{array}$ & $\begin{array}{l}\text { Posibilidad de crear una red } \\
\text { verde con la construcción de } \\
\text { corredores ecológicos. } \\
\text { Posibilidad de acceder a fuentes } \\
\text { de financiación a través de } \\
\text { ayudas al desarrollo. } \\
\text { Tutela por parte de la Unesco y } \\
\text { opciones de capacitación y } \\
\text { aprendizaje mutuo gracias a } \\
\text { formar parte de la red mundial } \\
\text { de Reservas de la Biosfera. } \\
\text { La existencia de diferentes } \\
\text { colectivos sociales que actuaron } \\
\text { de promotores para obtener la } \\
\text { designación de Reserva de la } \\
\text { Biosfera, pueden servir de } \\
\text { catalizadores para la transición } \\
\text { hacia políticas más participativas. }\end{array}$ \\
\hline
\end{tabular}

Fuente: elaboración propia

Por último, partiendo de que el objetivo principal de estas iniciativas es la provisión de servicios ecosistémicos, mediante la integración de los espacios, la permeabilidad de los desarrollos, la concienciación de la ciudadanía, etc., en la Tabla 4 desarrollamos una matriz CAME (CorregirAfrontar-Mantener-Explotar), derivada del análisis DAFO, con el fin de facilitar recomendaciones o aportaciones de futuro que puedan orientar a los planificadores a mejorar su trabajo. 


\section{Tabla 4. Matriz CAME (CORREGIR-AFRONTAR-MANTENER-EXPLOTAR)}

\begin{tabular}{|c|c|}
\hline \multicolumn{2}{|c|}{ OTTAWA } \\
\hline CORREGIR & AFRONTAR \\
\hline $\begin{array}{l}\text { Ampliar el desarrollo de leyes de protección del } \\
\text { paisaje agrícola. } \\
\text { Incrementar las densidades urbanas para evitar } \\
\text { crecimientos esponjados. }\end{array}$ & $\begin{array}{c}\text { El desarrollo de medidas para frenar el oligopolio } \\
\text { en el mercado inmobiliario. }\end{array}$ \\
\hline MANTENER & EXPLOTAR \\
\hline $\begin{array}{l}\text { Potenciar, en mayor medida, la participación } \\
\text { ciudadana y de la comunidad científica. }\end{array}$ & $\begin{array}{l}\text { La paulatina ampliación de la superficie protegida } \\
\text { incorporando los sistemas agrícolas. }\end{array}$ \\
\hline \multicolumn{2}{|c|}{ ONTARIO } \\
\hline CORREGIR & AFRONTAR \\
\hline $\begin{array}{c}\text { Profundizar en la integración de los distintos planes } \\
\text { dentro de una planificación estratégica coherente y } \\
\text { holística. }\end{array}$ & $\begin{array}{l}\text { El desarrollo de medidas para proteger los } \\
\text { acuíferos de Oak Ridges Moraine. } \\
\text { La articulación del desarrollo urbanístico y de las } \\
\text { infraestructuras hacia zonas no protegidas y de } \\
\text { menor valor ambiental y/o paisajístico. }\end{array}$ \\
\hline MANTENER & EXPLOTAR \\
\hline $\begin{array}{l}\text { Los elementos conectores de los grandes parques y } \\
\text { áreas naturales protegidas. }\end{array}$ & $\begin{array}{l}\text { El fomento de la actividad turística sostenible y de } \\
\text { ocio responsable en el anillo verde. }\end{array}$ \\
\hline \multicolumn{2}{|c|}{ SÃO PAULO } \\
\hline CORREGIR & AFRONTAR \\
\hline $\begin{array}{c}\text { El desarrollo de actividades de divulgación y } \\
\text { concienciación ciudadana sobre los beneficios de } \\
\text { la Iniciativa. }\end{array}$ & $\begin{array}{c}\text { La introducción de medidas correctoras para paliar } \\
\text { los impactos de la actividad minera. } \\
\text { El desarrollo de elementos conectores (corredores } \\
\text { ecológicos, greenways, sendas urbanas, etc.) para } \\
\text { evitar el aislamiento de determinadas áreas de la } \\
\text { Mata Atlántica. }\end{array}$ \\
\hline MANTENER & EXPLOTAR \\
\hline $\begin{array}{l}\text { La cooperación interinstitucional. } \\
\text { El fomento del empleo, especialmente el orientado } \\
\text { a los colectivos más vulnerables. }\end{array}$ & $\begin{array}{l}\text { La capacidad de atraer financiación extranjera para } \\
\text { el desarrollo de proyectos pilotos. }\end{array}$ \\
\hline
\end{tabular}

Fuente: elaboración propia

\section{Conclusiones}

Este artículo explora las complejidades de tres anillos verdes implementados en el continente americano (Ottawa, Ontario y São Paulo), con el fin de determinar si se ha producido una evolución de los mismos a la escala más amplia de infraestructuras verdes. Al rastrear el desarrollo y evolución del concepto de anillo verde, mostramos los considerables cambios experimentados por dicho concepto desde su introducción, hace ya más de un siglo, hasta la actualidad. A través de un análisis comparativo de la escala, la forma, las funciones y usos del suelo y el enfoque de gestión de los tres casos, mostramos también la consolidación de dichas iniciativas y su evolución hacia infraestructuras verdes más amplias, alcanzando esa mayor conectividad, multifuncionalidad y complejidad que caracteriza a las mismas, aunque con resultados desiguales en el cumplimiento de los objetivos de las políticas. Así, por ejemplo, 
en Ottawa, a pesar de que la mayor parte del suelo es de propiedad pública, esta iniciativa ha alcanzado un éxito parcial al no lograr contener el crecimiento urbano y permitir la promoción de la movilidad forzada debido al conocido efecto leapfrog, que promueve la urbanización discontinua más allá de las zonas protegidas. En el caso de Ontario, aunque las políticas del anillo verde han detenido la pérdida de tierras agrícolas dentro del mismo, también se ha producido el fenómeno leapfrog. Y en el caso de São Paulo, el avance de las políticas de protección socio-ambiental, donde se combina la protección y formación de jóvenes en riesgo de exclusión social con actuaciones de preservación y recuperación ambiental, se enfrenta a la creciente polarización económica y a las fuertes presiones urbanísticas propias de un país emergente. Por lo tanto, si bien el análisis comparativo muestra que, los anillos verdes han evolucionado hacia infraestructuras verdes al perseguir múltiples objetivos de política, los tres casos han producido resultados mixtos.

En este sentido, la investigación ha puesto de manifiesto, por un lado, que en los tres casos estudiados se plantean serios desafíos para la implementación de los múltiples ámbitos de políticas, puesto que se requiere disponer de una elevada capacidad de gobernanza que permita llevar a cabo una gestión coordinada compleja entre los diversos niveles de gobiernos, los diferentes municipios y otros intereses privados y públicos y, por otro lado, la necesidad de proyectos de infraestructuras verdes más integrados que se encuentren respaldados por otras políticas. Por lo tanto, la colaboración entre todos los actores involucrados resulta fundamental para una implementación efectiva de las políticas y los marcos integrados son necesarios para abordar de forma más eficaz la gestión de las infraestructuras verdes. Además, se necesita un seguimiento continuo, mediante el uso de indicadores, para medir y evaluar la efectividad de las políticas de infraestructuras verdes en el logro de sus objetivos y estas políticas deben actualizarse regularmente para reflejar, en cada momento, las cambiantes condiciones socioeconómicas.

A medida que el ritmo de expansión urbana avanza casi sin cesar en la mayor parte del mundo, las infraestructuras verdes están sometidas a una presión cada vez mayor por parte de los diferentes actores con intereses en conflicto (propietarios de la tierra, agricultores, promotores, especuladores, residentes, empresas, grupos ambientales, ONGs, turistas, etc.), siendo estos espacios verdes cada vez más importantes para el presente y para la planificación futura, ya que aportan innumerables servicios ecosistémicos. Por ello, se necesitan esfuerzos más ambiciosos para gestionar de forma más eficaz las infraestructuras verdes. En este contexto, los casos analizados de Ottawa, Ontario y São Paulo constituyen importantes activos ambientales, sociales 
y económicos para sus áreas de influencia, al tiempo que incorporan valiosa información para los actuales debates sobre infraestructuras verdes.

Agradecimientos: Las/os autoras/es agradecen el apoyo financiero del MINECO (ECO201676348-R, AEI/ FEDER, UE), del Gobierno Vasco (GIC 15/128 e IT-952-16) y de Izaskun Gómez de Salazar en la recopilación de datos.

Declaración responsable: Las/os autoras/es declaran que no existe ningún conflicto de interés con relación a la publicación de este artículo. Las/os tres autoras/es han participado en la revisión bibliográfica y la redacción del artículo. 


\section{Bibliografía}

Aguado, I., Barrutia, J.M., \& Echebarria, C. (2013). The green belt of Vitoria-Gasteiz. A successful practice for sustainable urban planning. Boletín de la Asociación de Geógrafos Españoles, (61), 181-193.

https://bage.age-geografia.es/ojs/index.php/bage/article/view/1551

Ahern, J. (2007). Green infrastructure for cities: The spatial dimension. In V. Novotny \& P. Brown (Eds.), Cities of the future: Towards integrated sustainable water and landscape management (pp. 267-283). IWA Publishing. https://doi.org/10.1.1.558.8386

Akimowicz, M., Cummings, H., \& Landman, K. (2016). Green lights in the Greenbelt? A qualitative analysis of farm investment decision-making in peri-urban Southern Ontario. Land Use Policy, 55, 24-36. http://dx.doi.org/10.1016/j.landusepol.2016.03.024

Ali, A.K. (2008). Greenbelts to contain urban growth in Ontario, Canada: Promises and prospects. Planning Practice and Research, 23(4), 533-548.

Allen, R., \& Campsie, P. (2013). Implementing the growth plan for the Greater Golden Horseshoe. Has the strategic regional vision been compromised? The Neptis Foundation. $\quad$ http://www.neptis.org/publications/implementing-growth-plan-greater-goldenhorseshoe

Amati, M. (2008). Urban green belts in the twenty-first century. In M. Amati (Ed.), Green belts: A twentieth-century planning experiment (pp. 1-17). Ashgate Publishing Limited.

Amati, M., \& Taylor, L. (2010). From green belts to green infrastructure. Planning Practice \& Research, 25(2), 143-155. https://doi.org/10.1080/02697451003740122

Amati, M., \& Yokohari, M. (2006). Temporal changes and local variations in the functions of London's green belt. Landscape and urban planning, 75(1-2), 125 142. https://doi.org/10.1016/j.landurbplan.2004.12.007

Andrés Orive, L., \& Dios Lema, R. (2012). Vitoria-Gasteiz, Spain: from greenbelt to regional green infrastructure. In T. Beatley (Ed.), Green Cities of Europe: Global Lessons on Green Urbanism (pp. 155-180). Island Press.

Aziz, T., \& Shah, M.U. (2019). Realized ecosystem services: using stakeholder theory for policy development. International Journal of Scientific Research and Engineering Development, 2(6), 379382. http://www.ijsred.com/volume2/issue6/IJSRED-V2I6P53.pdf 
Ballamingie, P., \& Walker, S.M. (2013). Field of dreams: just food's proposal to create a community food and sustainable agriculture hub in Ottawa, Ontario. Local Environment, 18(5), 529-542. https://doi.org/10.1080/13549839.2013.787975

Baptiste, A.K., Foley, C., \& Smardon, R. (2015). Understanding urban neighborhood differences in willingness to implement green infrastructure measures: a case study of Syracuse, NY. Landscape and Urban Planning, 136, 1-12. https://doi.org/10.1016/j.landurbplan.2014.11.012

Barbati, A., Corona, P., Salvati, L., \& Gasparella, L. (2013). Natural forest expansion into suburban countryside: Gained ground for a green infrastructure? Urban Forestry \& Urban Greening, 12(1), 36-43. https://doi.org/10.1016/j.ufug.2012.11.002

Bartesaghi Koc, C., Osmond, P., \& Peters, A. (2017). Towards a comprehensive green infrastructure typology: a systematic review of approaches, methods and typologies. Urban Ecosystems, 20(1), 15-35. https://doi.org/10.1007/s11252-016-0578-5

Baxendale, C., \& Buzai, G.D. (2019). Modelos urbanos e infraestructura verde en ciudades de América Latina. Análisis en la ciudad de Buenos Aires. Huellas, 23(2), 79106. http://dx.doi.org/10.19137/huellas-2019-2313

Baxter, P., \& Jack, S. (2008). Qualitative case study methodology: Study design and implementation for novice researchers. The Qualitative Report, 13(4), 544559. http://legacy.aosp.bo.it/reparti_servizi/evidencebasednursing/nuovo/Formazione/maste rebp_vecchi/master_2013_2014/Slide_corso_ricerca_2104/qualitativa/Baxter_lack_2008_Cas e_Study.pdf

Benedict, M.A., \& McMahon, E.T. (2012). Green infrastructure: linking landscapes and communities. Island press.

Bengston, D.N., \& Youn, Y.C. (2006). Urban containment policies and the protection of natural areas: the case of Seoul's greenbelt. Ecology and Society, 17(1). https://www.jstor.org/stable/26267777

Breiling, M., \& Ruland, G. (2008). The Vienna Green Belt: From localised protection to a regional concept. In M. Amati (Ed.), Urban Green Belts in the Twenty-first Century (pp. 167-183). Ashgate.

Caldwell, W., \& Proctor, K. (2013). Farming in Ontario's greenbelt: Possibility grows here. Friends of the Greenbelt Foundation.

https://www.greenbelt.ca/farming_in_ontario_s_greenbelt_possibility_grows_here 
Caldwell, W., \& Temple, K. (2009). Canada's Capital Greenbelt: moving towards sustainable agriculture. National Capital Commission.

http://waynecaldwell.ca/Publications/Moving_Towards_Sustainable_Agriculture\%20(1)\%20\%20final\%20report.pdf

Campbell, M.O. (2019). Adaptive Management of Green Spaces and Life Quality in Glasgow (Scotland) and Ottawa (Canada). In B. Sinha (Ed.), Multidimensional Approach to Quality of Life Issues. A Spatial Analysis (pp. 417-431). Springer. https://doi.org/10.1007/978-981-13-6958$\underline{2} 26$

Carter-Whitney, M. (2010). Ontario's greenbelt in an international context. Friends of the Greenbelt Foundation.

https://www.greenbelt.ca/ontario_s_greenbelt_in_an_international_context2010

Chang, Q., Li, X., Huang, X., \& Wu, J. (2012). A GIS-based green infrastructure planning for sustainable urban land use and spatial development. Procedia Environmental Sciences, 12, 491498. https://doi.org/10.1016/j.proenv.2012.01.308

City of Ottawa (2021). Open Ottawa. Open data, maps, apps \& stories from the City of Ottawa. https://open.ottawa.ca/

Côté, A., \& Fenn, M. (2014). Provincial-municipal relations in Ontario: Approaching an inflection point. Institute on Municipal and Governance. https://munkschool.utoronto.ca/imfg/uploads/275/1560_imfg_no_17_online_ful I_colour.pdf

Coutts, C., \& Hahn, M. (2015). Green infrastructure, ecosystem services, and human health. International Journal of Environmental Research and Public Health, 12(8), 97689798. https://doi.org/10.3390/ijerph120809768

Daniels, T.L. (2010). The use of greenbelts to control sprawl in the United States. Planning Practice \& Research, 25(2), 255-271. https://doi.org/10.1080/02697451003740288

Davies, C., \& Lafortezza, R. (2017). Urban green infrastructure in Europe: Is greenspace planning and policy compliant? Land Use Policy, 69, 93101. https://doi.org/10.1016/j.landusepol.2017.08.018

Davies, C., MacFarlane, R., McGloin, C., \& Roe, M. (2006). Green Infrastructure Planning Guide. North-East Community Forests.

http://www.aughty.org/pdf/green_infrastruct_planguide.pdf 
Deaton, B.J., \& Vyn, R.J. (2015). The effect of Ontario's Greenbelt on the price of vacant farmland. Canadian Journal of Agricultural Economics, 63(2), 185 208. https://doi.org/10.1111/cjag. 12045

Douglas, O., Lennon, M., \& Scott, M. (2017). Green space benefits for health and well-being: A life-course approach for urban planning, design and management. Cities, 66, 5362. https://doi.org/10.1016/j.cities.2017.03.011

Echeverry, J.D. (2019). Medellín: A city of Crossroads. Poverty, City Model and Social Change in the Green Belt Project. Territorios, (40), 273289. http://dx.doi.org/10.12804/revistas.urosario.edu.co/territorios/a.5535

Erickson, D. (2004). The relationship of historic city form and contemporary greenway implementation: A comparison of Milwaukee, Wisconsin (USA) and Ottawa, Ontario (Canada). Landscape and Urban Planning, 68(2-3), 199-221. https://doi.org/10.1016/S01692046(03)00160-9

European Commission (2013). Communication from the Commission to the European Parliament, the Council, the European Economic and Social Committee and the Committee of the Region. Green Infrastructure (Gl)-Enhancing Europe's natural capital (COM/2013/0249 final). http:/ / eur-lex.europa.eu/legal-content/EN/TXT/?uri=CELEX:52013DC0249

Evans, C., \& Freestone, R. (2010). From greenbelt to green web: regional open space planning in Sydney, 1948-1963. Planning Practice \& Research, 25(2), 223240. https://doi.org/10.1080/02697451003740254

Feria Toribio, J.M., \& Santiago Ramos, J. (2017). Naturaleza y ciudad. Perspectivas para la ordenación de la infraestructura verde en los planes territoriales metropolitanos en España. Boletín de la Asociación de Geógrafos Españoles, (74). https://doi.org/10.21138/bage.2447

Fung, F., \& Conway, T. (2007). Greenbelts as an environmental planning tool: a case study of southern Ontario, Canada. Journal of Environmental Policy and Planning, 9(2), 101117. https://doi.org/10.1080/15239080701381355

Garmendia, E., Apostolopoulou, E., Adams, W.M., \& Bormpoudakis, D. (2016). Biodiversity and green infrastructure in Europe: boundary object or ecological trap? Land Use Policy, 56, 315319. https://doi.org/10.1016/j.landusepol.2016.04.003 
Gordon, D., \& Scott, R. (2008). Ottawa's greenbelt evolves from urban separator to key ecological planning component. In M. Amati (Ed.), Urban greenbelts in the twenty-first century (pp. 129-149). Routledge.

Grădinaru, S.R., \& Hersperger, A.M. (2019). Green infrastructure in strategic spatial plans: Evidence from European urban regions. Urban Forestry \& Urban Greening, 40, 1728. https://doi.org/10.1016/j.ufug.2018.04.018

Greenbelt Coalition of Canada's Capital Region (2010). Greenbelt Coalition's Position Paper for the NCC's Greenbelt Master Plan Review.

http://www.renaud.ca/public/NCC_Related/GreenbeltCoalition_PositionPaperSeptember\%202010-Working_Copy_for_NCC_Review.pdf

Han, A.T., \& Go, M.H. (2019). Explaining the national variation of land use: A cross-national analysis of greenbelt policy in five countries. Land Use Policy, 81, 644656. https://doi.org/10.1016/j.landusepol.2018.11.035

Hansen, R., \& Pauleit, S. (2014). From multifunctionality to multiple ecosystem services? A conceptual framework for multifunctionality in green infrastructure planning for urban areas. AMBIO, 43, 516-529. https://doi.org/10.1007/s13280-014-0510-2

Henstra, D. (2017). Local government and politics in Ontario. In C.Collier, \&J. Malloy (Eds.), The politics of Ontario (pp. 118-134). University of Toronto Press.

Instituto Florestal (2021). Reserva da Biosfera do Cinturão Verde da Cidade de São

Paulo. https://www.infraestruturameioambiente.sp.gov.br/institutoflorestal/o-instituto/rbcv/e Instituto Florestal - IF/SMA (2021). Infraestrutura de dados espaciais ambientais do estado de São Paulo - IDEA-SP. https://datageo.ambiente.sp.gov.br/

Johns, C.M. (2019). Understanding barriers to green infrastructure policy and stormwater management in the City of Toronto: a shift from grey to green or policy layering and conversion? Journal of Environmental Planning and Management, 62(8), 1377 1401. https://doi.org/10.1080/09640568.2018.1496072

Jun, M.J., \& Bae, C.H.C. (2000). Estimating the commuting costs of Seoul's greenbelt. International Regional Science Review, 300315. https://doi.org/10.1177/016001700761127416 
Keil, R., \& Macdonald, S. (2016). Rethinking urban political ecology from the outside in: greenbelts and boundaries in the post-suburban city. Local Environment, 21(12), 15161533. https://doi.org/10.1080/13549839.2016.1145642

Kipper, K. (2021). The City of Ottawa's Smart Growth Challenge: What Can We Expect from the New Official Plan? Carleton Perspectives on Public Policy, 7, 93119. https://ojs.library.carleton.ca/index.php/cpopp/article/view/3181

Korosteleva, M.V., \& Korosteleva, N.V. (2018). Forest-park green belts as environment-forming element of urbanized territories. In IOP Conference Series: Materials Science and Engineering, 451(1), 012158. https://iopscience.iop.org/article/10.1088/1757-899X/451/1/012158/meta

Kühn, M. (2003). Greenbelt and Green Heart: separating and integrating landscapes in European city regions. Landscape and Urban Planning, 64(1-2), 19-

\section{7. https://doi.org/10.1016/S0169-2046(02)00198-6}

Lafortezza, R., Davies, C., Sanesi, G., \& Konijnendijk, C. C. (2013). Green Infrastructure as a tool to support spatial planning in European urban regions. iForest-Biogeosciences and Forestry, 6(3), 102. https://doi.org/10.3832/ifor0723-006

Lemes de Oliveira, F. (2019). Green Wedges: The Resilience of a Planning Idea. In F. Lemes de Oliveira \& I. Mell (Eds.), Planning Cities with Nature. Cities and Nature. Springer. https://doi.org/10.1007/978-3-030-01866-5_2

Macdonald, S., \& Keil, R. (2012). The Ontario greenbelt: shifting the scales of the sustainability fix?. The Professional Geographer, 64(1), 145. https://doi.org/10.1080/00330124.2011.586874

Macdonald, S., Monstadt, J., \& Friendly, A. (2021). Rethinking the governance and planning of a new generation of greenbelts. Regional Studies 55(5), 804817. https://doi.org/10.1080/00343404.2020.1747608

Mansor, M., Said, I., \& Mohamad, I. (2012). Experiential contacts with green infrastructure's diversity and well-being of urban community. Procedia-Social and Behavioral Sciences, 49, 257267. https://doi.org/10.1016/j.sbspro.2012.07.024

Mell, I.C. (2017). Green infrastructure: reflections on past, present and future praxis. Landscape Research, 42(2), 135-145. https://doi.org/10.1080/01426397.2016.1250875

Ministry of Municipal Affairs and Housing (2017). The Greenbelt Plan. https://files.ontario.ca/greenbelt-plan-2017-en.pdf 
Ministry of Municipal Affairs and Housing (2020a). A Place to Grow: Growth plan for the Greater Golden Horseshoe. https://www.ontario.ca/document/place-grow-growth-plan-greater-golden$\underline{\text { horseshoe }}$

Ministry of Municipal Affairs and Housing (2020b). Ontario's Greenbelt. https://www.ontario.ca/page/ontarios-greenbelt

Monclús, J. (2018). From Park Systems and Green Belts to Green Infrastructures. In C. Díez Medina \& J. Monclús (Eds.), Urban Visions. From Planning Culture to Landscape Urbanism (pp. 269-278). Springer. https://doi.org/10.1007/978-3-319-59047-9_26

Monteiro, R., Ferreira, J.C., \& Antunes, P. (2020). Green Infrastructure Planning Principles: An Integrated Literature Review. Land, 9(12), 525. http://dx.doi.org/10.3390/land9120525

Moraes Victor, R.A.B., Costa Neto, J. de Brito, Nacib Ab'Saber, A., Serrano, O., Domingos, M., Camacho Pires, B.C., Amazonas, M., \& Moraes Victor, M.A. (2004). Application of the Biosphere Reserve concept to urban areas: the case of São Paulo City Green Belt Biosphere Reserve, Brazil-São Paulo Forest Institute: a case study for UNESCO. Annals of the New York Academy of Sciences, 1023(1), 237-281. https://doi.org/10.1196/annals. 1319.012

Moreno-Peñaranda, R. (2021). Synergies in Urban Environmental Policy: Ecosystem Services and Biodiversity Co-benefits in São Paulo City, Brazil. In K. Ito (Ed.), Urban Biodiversity and Ecological Design for Sustainable Cities (pp. 243-272). https://doi.org/10.1007/978-4-431-56856-8_11

Morrison, N. (2010). A Green Belt under Pressure: The Case of Cambridge, England. Planning Practice \& Research, 25(2), 157-181. https://doi.org/10.1080/02697451003740189

National Capital Commission (NCC) (2013). Canada's Capital Greenbelt Master Plan. Ottawa: National Capital Commission. https://ncc-website-2.s3.amazonaws.com/documents/final-2013greenbelt-master-plan-en. pdf? mtime=20181121104505\&focal=none

National Capital Commission (NCC) (2021). Canada's Capital Greenbelt. https://nccccn.gc.ca/places/greenbelt

Natural England (2008). Green infrastructure strategies. An introduction for local authorities and their partners. http://publications. naturalengland.org.uk/publication/36010

Naumann, S., Davis, M., Kaphengst, T., Mav Pieterse, M., \& Rayment, M., (2011). Design, implementation and cost elements of Green Infrastructure projects. Final report to the European Commission, DG Environment, Contract no. 070307/2010/577182/ETU/F.1, Ecologic institute and GHK Consulting. https://www.ecologic.eu/11382 
Oliveira, S., Andrade, H., \& Vaz, T. (2011). The cooling effect of green spaces as a contribution to the mitigation of urban heat: A case study in Lisbon. Building and Environment, 46(11), 21862194. https://doi.org/10.1016/j.buildenv.2011.04.034

Ontario Ministry of Northern Development, Mines, Natural Resources and Forestry (2021). Ontario GeoHub, Land Information Ontario. https://geohub.lio.gov.on.ca/

Opdam, P., Steingröver, E., \& Van Rooij, S. (2006). Ecological networks: A spatial concept for multi-actor planning of sustainable landscapes. Landscape and Urban Planning, 75(3-4), 322332. https://doi.org/10.1016/j.landurbplan.2005.02.015

Pauleit, S., Ambrose-Oji, B., Andersson, E., Anton, B., Buijs, A., Haase, D., Elands, B., Hansen, R., Kowarik, I., Kronenberg, J., Mattijssen, T., Stahl Olafsson, A., Rall, E., van der Jagt, A.P.N., \& van den Bosch, C.K. (2019). Advancing urban green infrastructure in Europe: Outcomes and reflections from the GREEN SURGE project. Urban Forestry \& Urban Greening, 40, 416. https://doi.org/10.1016/j.ufug.2018.10.006

Pond, D. (2009a). Institutions, political economy and land-use policy: greenbelt politics in Ontario. Environmental Politics, 238256. https://doi.org/10.1080/09644010802682619

Pond, D. (2009b). Ontario's Greenbelt: Growth management, farmland protection, and regime change in southern Ontario. Canadian Public Policy, 35(4), 413432. https://doi.org/10.3138/cpp.35.4.413

Prentice, M. (2012). A belt too tight. Ottawa Business Journal. http://www.obj.ca/Opinion/2012-10-12/article-3086074/A-belt-too-tight/1

Ruggia, O., \& Occhionero, F. (2019). El cinturón verde de Córdoba como factor clave para la soberanía alimentaria y el Derecho a la Ciudad. Cardinalis, 7(13), 117135. https://revistas.unc.edu.ar/index.php/cardi/article/view/27147

Ramos-Ribeiro, R. (2015). Green Belt Biosphere Reserve in the Brazilian City of São Paulo. Ecological Questions, 20, 93-97. http://dx.doi.org/10.12775/EQ.2014.021

Retrieved from Koc, C., Osmond, P., \& Peters, A. (2016). Towards a comprehensive green infrastructure typology: a systematic review of approaches, methods and typologies. Urban Ecosystems, 20(1), 15-35. https://doi.org/10.1007/s11252-016-0578-5

Rodrigues, A.E., Moraes Victor, R.A.B., \& Camacho Pires, B.C. (2006). A Reserva da Biosfera do Cinturão Verde da Cidade de São Paulo como marco para a gestão integrada da cidade, 
seus serviços ambientais e o bem-estar humano. São Paulo em Perspectiva, 20(2), 71 89. http://produtos. seade.gov.br/produtos/spp/v20n02/v20n02_06.pdf

Rodrigues, E.A. (Ed.) (2018). Ecosystem services and human well-being in the in the São Paulo City Green Belt Biosphere Reserve. Instituto

Florestal. https://www.infraestruturameioambiente.sp.gov.br/institutoflorestal/2018/12/ecosyst em-services-and-human-well-being-in-the-sao-paulo-city-green-belt-biosphere-reserve/

Rodrigues, E.A., Alves Pereira de Andrade, D., Camacho Pires, B.C., \& Victor, R.A.B.M. (2007). El enfoque ecosistémico en la gestión de las áreas urbanas y periurbanas: contribución de la reserva de la biosfera del cinturón verde de la ciudad de Sao Paulo para la gestión integrada de las ciudades y de sus servicios ambientales. In Hacia una cultura de conservación de la diversidad biológica (pp. 337-353). Sociedad Entomológica Aragonesa, SEA. http://seaentomologia.org/PDF/PDFSM3MVOL6/Pdf3633735436Rodrigues.pdf

Sanesi, G., Colangelo, G., Lafortezza, R., Calvo, E., \& Davies, C. (2017). Urban green infrastructure and urban forests: A case study of the Metropolitan Area of Milan. Landscape Research, 42(2), 164-175. https://doi.org/10.1080/01426397.2016.1173658

Seiwert, A., \& Rößler, S. (2020). Understanding the term green infrastructure: origins, rationales, semantic content and purposes as well as its relevance for application in spatial planning. Land Use Policy, 97, 104785. https://doi.org/10.1016/j.landusepol.2020.104785

Siedentop, S., Fina, S., \& Krehl, A. (2016). Greenbelts in Germany's regional plans-An effective growth management policy? Landscape and Urban Planning, 145, 71 82. https://doi.org/10.1016/j.landurbplan.2015.09.002

Slätmo, E., Nilsson, K., \& Turunen, E. (2019). Implementing green infrastructure in spatial planning in Europe. Land, 8(4), 62. https://doi.org/10.3390/land8040062

Sturzaker, J., \& Mell, I. (2017). Green belts: Past; present; future? Routledge.

Tang, B.S., Wong, S.W., \& Lee, A.K.W. (2007). Green belt in a compact city: A zone for conservation or transition? Landscape and Urban Planning, 79(3-4), 358373. https://doi.org/10.1016/j.landurbplan.2006.04.006

Taylor, J., Paine, C., \& FitzGibbon, J. (1995). From greenbelt to greenways: four Canadian case studies. Landscape and urban planning, 33(1-3), 47-64. https://doi.org/10.1016/01692046(94)02013-6 
Taylor, L. (2019). The future of green belts. In Scott, M., Gallent, N. and Gkartzios, M. (Eds). Routledge companion to rural planning. (pp. 458-468). Routledge.

The Greenbelt Foundation (2021). Ontario's Greenbelt. https://www.greenbelt.ca

Thomas, K., \& Littlewood, S. (2010). From green belts to green infrastructure? The evolution of a new concept in the emerging soft governance of spatial strategies. Planning Practice \& Research, 25(2), 203-222. https://doi.org/10.1080/02697451003740213

Timpe, A. (2020), Cultivating the Cologne Green Belt: The Belvedere Agricultural Park. In L. Scazzosi, \& P. Branduini (Eds.), AgriCultura. Urban Agriculture (pp. 205-224). Springer. https://doi.org/10.1007/978-3-030-49012-6_13

Tzoulas, K., Korpela, K., Venn, S., Yli-Pelkonen, V., Kaźmierczak, A., Niemela, J., \& James, P. (2007). Promoting ecosystem and human health in urban areas using Green Infrastructure: A literature review. Landscape and Urban Planning, 81(3), 167178. https://doi.org/10.1016/j.landurbplan.2007.02.001

Vyn, R.J. (2012). Examining for evidence of the leapfrog effect in the context of strict agricultural zoning. Land Economics, 88(3), 457-477. http://www.jstor.org/stable/23272622

Weber, T., Sloan, A., \& Wolf, J. (2006). Maryland's Green Infrastructure Assessment: Development of a comprehensive approach to land conservation. Landscape and Urban Planning, 77(1-2), 94-110. https://doi.org/10.1016/j.landurbplan.2005.02.002

Wright, H. (2011). Understanding green infrastructure: the development of a contested concept in England. Local Environment, 10031019. https://doi.org/10.1080/13549839.2011.631993

Xie, X., Kang, H., Behnisch, M., Baildon, M., \& Krüger, T. (2020). To what extent can the green belts prevent urban sprawl? - a comparative study of Frankfurt am Main, London and Seoul. Sustainability, 12(2), 679. https://doi.org/10.3390/su12020679

Yokohari, M., Takeuchi, K., Watanabe, T. and Yokota, S. (2000). Beyond greenbelts and zoning: A new planning concept for the environment of Asian mega-cities. Landscape and Urban Planning, 47(3-4), 159-171. https://doi.org/10.1007/978-0-387-73412-5_50

Young, R., Zanders, J., Lieberknecht, K., \& Fassman-Beck, E. (2014). A comprehensive typology for mainstreaming urban green infrastructure. Journal of Hydrology, 519, 2571 2583. https://doi.org/10.1016/j.jhydrol.2014.05.048 
Zhang, Z., Meerow, S., Newell, J.P., \& Lindquist, M. (2019). Enhancing landscape connectivity through multifunctional green infrastructure corridor modeling and design. Urban Forestry \& Urban Greening, 38, 305-317. https://doi.org/10.1016/j.ufug.2018.10.014 